THE GAMMA-GLUTAMYL BOND IN CHICK EMBRYO COLLAGEN

\title{
WILLIAM PRATI
}

1964 


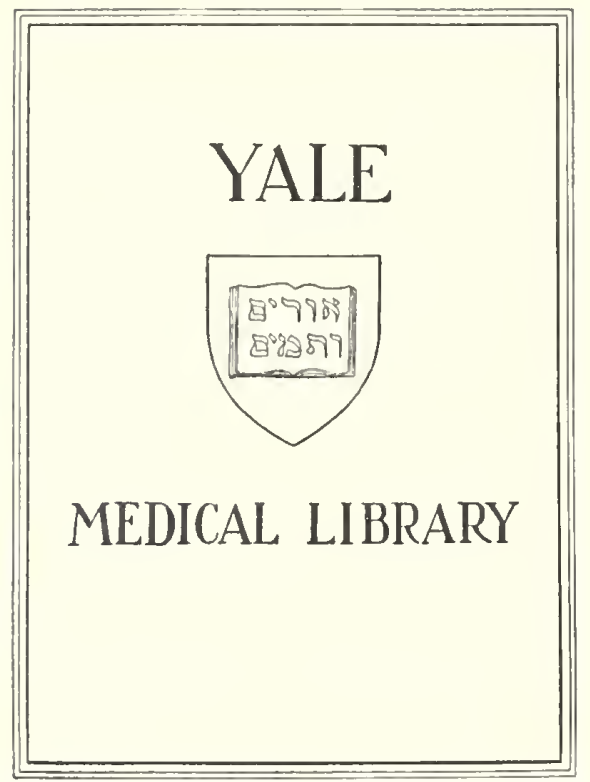




\section{Digitized by the Internet Archive in 2017 with funding from Arcadia Fund}





The r-GIutamyl Bond in Ghick Embryo Collagen

\section{By:}

William Brewster Pratt

B.A., Dartmouth College, 1960

A thesis Presented to the Faculty and officers of the Yale University School of Medicine in partial fulfillment of the requirements for the degree of Doctor of Medicine

$$
\text { Apri1, } 1964
$$

Department of Biochemistry

Yale University School of Medicine 
-

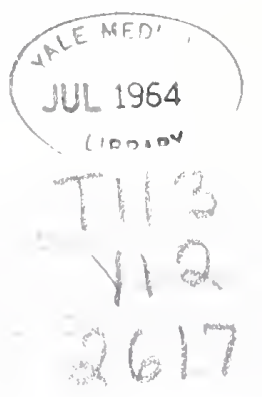


Acknowledgement

The author would Iike to thank Dr. Lewis Lukens for his patient guidance and encouragement in both the experimento ation and in the writing of the thesis. 



\section{Tabie of Contents.}

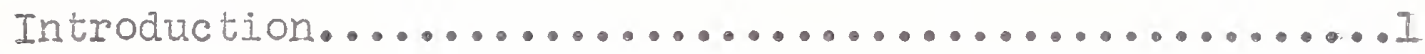

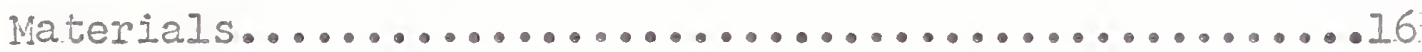

Methods...................................19

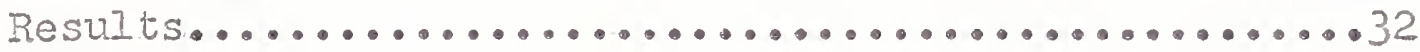

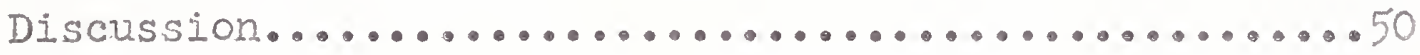

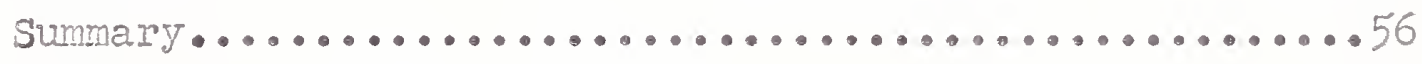

Bibliography.............................58 



\section{Introduction.}

Quastel, Stewart, and Tunicliffe in 1923 (I) were the first to present evidence for the existence of gamma-glutamyl peptide linkages in a naturally occuring substance, glutathione, which had been isolated from yeast and demonstrated in various animal tissues by Hopkins in 1921 (2). Using the observation of Dakin (3) that alpha-amino acids, oxidized with hydrogen peroxide in the presence of a trace of iron salt, yield carboxylic acids with one carbon less than the original compound, quastel et al. were able to oxidize impure preparations of glutathione with hydrogen peroxide and after acid hydrolysis to identify succinic acid among. the products. This evidence suggested that the glutamic acid in glutathione was joined to the tripeptide through its gamma-carboxyl group leaving its alpha amino carboxylic grouping open to attack by the oxidizing agent. Kendall et al. (4) were able to demonstrate that oxidation of crystalline glutathione with hypobronite or Chloramine T did not disrupt the peptide bonds but did form products that yielded succinic acid on hydrolysis. The final proof for the presence of gamma-Iinkage in glutathione was offered by Harrington and Head (5) who synthesized gamma-glutamylcysteinylglycine and showed that its 

properties were identical. with those of the crystalline peptide.

In 1937 Ivanovics and Brucknex (6) isolated and purified the capsular substance of. Bacilius anthracis and Bacillus subtilis. On hydrolysis of the material they found only glutamic acid, but they were not able to say that the protein was made up solely of this amino acid. They pointed out that, if the capsular substance contained only glutamic acid, then two isomeric forms are possible depending on Whether the alpha-carboxyl or the gamma-carbozyl or both are involved in the peptide linkages. (Figo 1)。

Bovarnick (7) was able by comparison of total nitrogen to glutamic acid nitrogen to show that the capsular substance of Bacillus subtilis consisted solely of glutamic acid units. Working on the assumption that racemization of the glutamic acid units in alkaline solution would not occur if a free carboxyl was situated adjacent to the asymetric carbon atom (gamma-glutamyl form), Bovarnicls allowed. purified capsular substance to stand for ten days in alkaIine solution. There was no change in optical rotation of the solution over this period - amino nitrogen showed only a small increase - from 10 to 20\% - demonstrating that significant hydrolysis which would prevent racemization. 

(3)

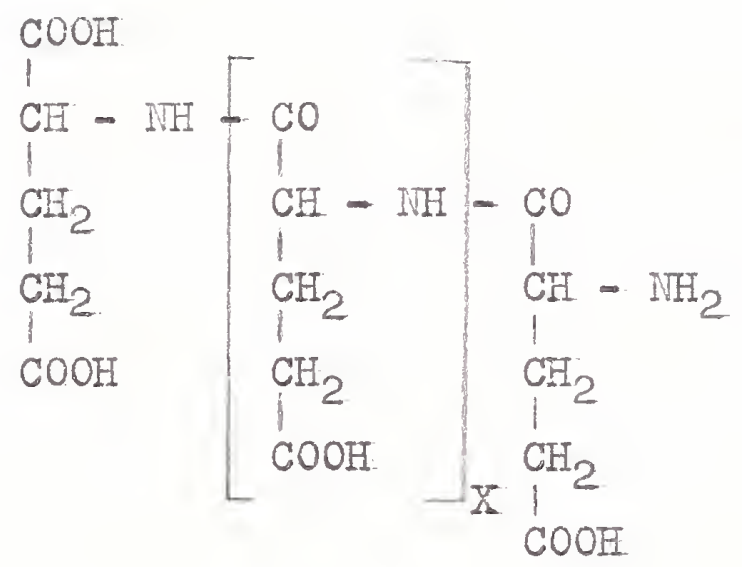

Alpha-Iinkage

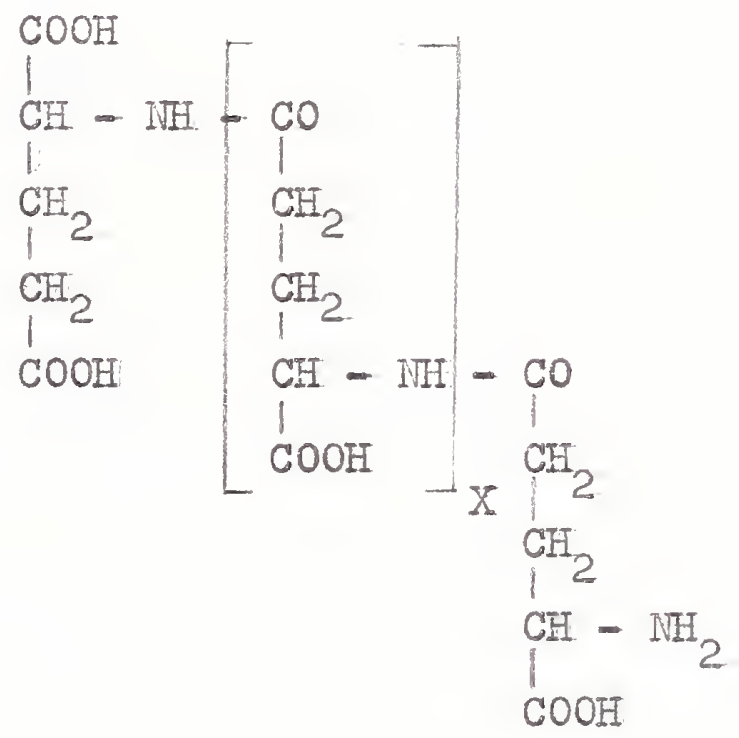

Gamma-Iinkage

Fig. I. Structure of the alpha- and gamma-peptide linkages. 
, 
had not occurred. Gamma-peptide Iinkage of the glutamic acid was indicated on this basis. In support of this conclusion, a biuret test, which is specific for alpha-linked units, was negative.

Further evidence in support of a homogenous composition for the capsular substance was provided when Hanby and Rydon (8) converted the glutamic acid obtained from hydrolysis of Bacillus anthracis hapten to pyrrolioone-carboxylic acid and isolated this product quantitatively by chromatography on silica gel, thus verifying that the capsular substance was composed solely of glutamic acid unitso The ready fission of the capsular substance by acid indicated to these investigators that the glutamic acid residues were Iinked, in part at least, by linkages which were more suseeptible: to acid hydrolysis tha:n alpha-peptide bonds. They noticed that during Van SIyke amino-nitrogen assays the apparent amino nitrogen content of the capsular substance increased (the apparent molecular weight decreased) with increasing reaction time, a finding which indicated to the authors that in addition to the free amino group, the capsular substance also contained gamma-peptide groupings which Iiberated their nitrogen mole slowly under Van slyke conditions. One sample submitted to this procedure (molecular. 

$\mathrm{NH}_{2}$

$\mathrm{R} \cdot \mathrm{CO} \cdot \mathrm{NH} \cdot \mathrm{CH} \cdot \mathrm{CONHR}^{\prime}$

$$
\left(\mathrm{CH}_{2}\right)_{2}+\mathrm{NH}_{2} \mathrm{R}^{8}+\mathrm{RCOOH}
$$

Alpha-glutamy peptide Alpha, gamra-diaminobutyric acid

$\mathrm{R} \cdot \mathrm{CO} \cdot \mathrm{NII} \cdot \frac{\mathrm{CH}}{\mathrm{X}} \cdot \mathrm{CH}_{2} \cdot \mathrm{CH}_{2} \cdot \mathrm{CO} \cdot \mathrm{NHR}^{1}-$

$$
\begin{aligned}
& \mathrm{O}=\mathrm{CH} \cdot \mathrm{CH}_{2} \cdot \mathrm{CH}_{2} \cdot \mathrm{COOH} \\
& +2 \mathrm{NH}_{3}+\mathrm{NH}_{2} \mathrm{R}^{2}+\mathrm{RCOOH}
\end{aligned}
$$

Gamma-glutamy peptide

Succinic semialdehyde

Fig. 2. Conversion of the alpha- and gamma-glutarny peptides to the polyhydrazide followed by Curtius degradation. Unaltered polypeptide, $\mathrm{X}=\mathrm{COOH}$; polymethyl ester, $\mathrm{X}=\mathrm{COOCH} ;$ polyhydrazide, $\mathrm{X}=\mathrm{CO}$. $\mathrm{NH}$ - $\mathrm{NH}_{2}$; product of Curtius degradation, $\mathrm{X}=\mathrm{NH}_{3}$ 

weight 5000) showed onIy a slight increase in amino-nitrogen with reaction time and they felt that this represented a final degradation product composed solely of alpha-peptide linkage, the gamma-linkages having been hydrolyzed by acid during the preparation.

Kovacs and Bruckner (9) (Fig. 2.) converted the polyD-glutamic acid of Bacillus subtilis into the polymethyl. ester and then into the polyhydrazide. After Curtius degradation followed by acid hydrolysis only succinic semialdehyde (the gama-Iinkage rearrangement product) was found in the hydrolysate - there was no alpha, gamma-diaminobutyric acid. This indicated that in native poly-D-glutamic a.cid gamma-glutamyl bonds predominated. Iater, Kovacs, Bruckner, and Kovacs (10) subjected alpha-I-polyglutamic. acid hydrazide to the curtius procedure and on hydrolysis recovered only alpha, gamna-diaminobutyric acid. Bruckner, Kovacs, and Iagy (II) then converted methyl poly-D-glutamate (prepared fror the capsule of Bacillus subtilis) into the polyamide which was submitted to Hofmann degradation. After hydrolysis of the rearranged product only succinic semialdehyde was recovered.

Waley (12) synthesized Poly-(gamma-I-glutamyI)-I-gIutamic acid. Many of its properties (eg. solubility in waterg ionization constant, infra-red spectra, and reactivity to ninhydrin) were similar to those of Bacillus subtilis and 

Bacillus licheniformis and differed from those of a synthetic alpha-linked polypeptide.

Chibnall, Rees, and Richards (13) esterified several samples of poly-glutamic acid from Bacillus subtilis, reduced them with lithium borohydride and analyzed the products given on subsequent acid hydrolysis. Under these conditions an alpha-linked glutamyl unit would be expected to yield delta-hydroxy-alpha-aminovaleric acid:

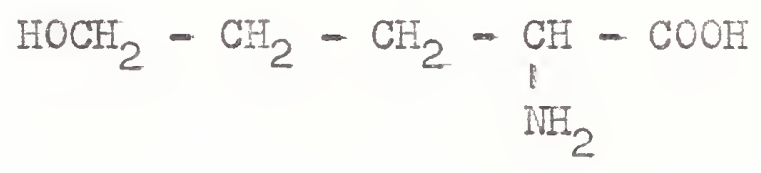

and a gamma-linked glutamyl unit would yield delta-hydroxygama-aminovaleric acid:

$$
\mathrm{HOCH}_{2}-\underset{\substack{\mathrm{NH}_{2} \\ \mathrm{H}_{2}}}{\mathrm{CH}}-\mathrm{CH}_{2}-\mathrm{CH}_{2}-\mathrm{COOH}
$$

Only the latter product was found, thus affirming the solely gamma-linked nature of the capsular substance. A synthetic poly-alpha-glutamic acid methyl ester treated in the same manner yielded $77.8 \%$ of total. $N$ as delta-hydroxy-alphaaminovaleric acid and none as the gamma-linked reduction product.

Sihce the work on capsular substance was carried out, gama-glutamyl linkages, have been found in several matural 



\section{(8)}

substances, a most interesting example being the presence of these bonds in collagen as ascertained by Gallop, Seifter et al (14).

These investigators noted that the conditions necessary to bring about Hofmann and Curtius rearrangements (references 9-11) when applied to proteins on a. small scale, require drastic conditions and are often non-quantitative. In view of this, they studied the application of the Lossen rearrangement of the dinitrophenyl derivatives of hydroxamic acids to analysis of carbozyl groups in several compounds including a commercial base processed gelatin obtained from pig skin. Gallop et al. felt that the relative mildness of the conditions eraployed endowed the reactions with greater specificity. They esterified gelatin with methanol and acetic anhydride, formed the hydroxamic acid derivative by adding the methyl ester to neutral aqueous hydroxylamine, reacted the hydroxamate with FDIB ${ }^{\text {I }}$ at pH 7.0 and promoted Lossen rearrangement of the hydroxamate-DINP derivative: by heating at $100^{\circ} \mathrm{C}$. for $2 \mathrm{~min}$. in. 0.1. IN ITaOH. After a.cid hydrolysis the rearrangement products, alpha,gama-diaminobutyric acid in the case of alpha-linkage

1. The abbreviation used is: FDINB, fluorodinitrobenzene. 



\section{(9)}

and succinic semialdehyde from gamma-Iinkage, were isolated (Fig. 3.). The presence of succinic semialdehyde was ascertained by forming the 2,4-dinitrophenylhydrazone and chromatographing against an authentic sample. Elution os the phenylhydrazone from the paper resulted in variable recoveries thereby limiting the procedure to a qualitative evaluation.

The authors note that the conditions of the procedure may promote interconversion of the alpha- and gamma-glutanyl peptide bonds. The esterification procedure was carried out in the presence of a dehydrating agent which could promote imide formation in the gelatin. Further, the gammaglutarny esters in the protein when undergoing attack by hydroxylamine under raild alkaline conditions wight be convep ted to imide intermediates. In either case the imide intermediates could be cleaved with the formation of gamma instead of alpha peptide bonds (Fig. 4.). Thus the appearance of succinic semialdehyde in the hydrolysate of the rearranged gelatin preparation provided strong but not. absolute evidence of gamma-linkage.

From their analysis of the hydrolysates of the pre-and post- rearranged gelatin, the authors observed that there was no serious discrepancy between the number of residues 
$\mathrm{R}-\mathrm{C}_{\mathrm{OHI}}^{\prime \prime} \frac{\text { methanol }}{\text { acetic anhydride }} \mathrm{R}-\mathrm{C}_{\mathrm{O}}^{\prime \prime} \quad \frac{\text { neutral aqueous }}{3}$ hydroxylamine

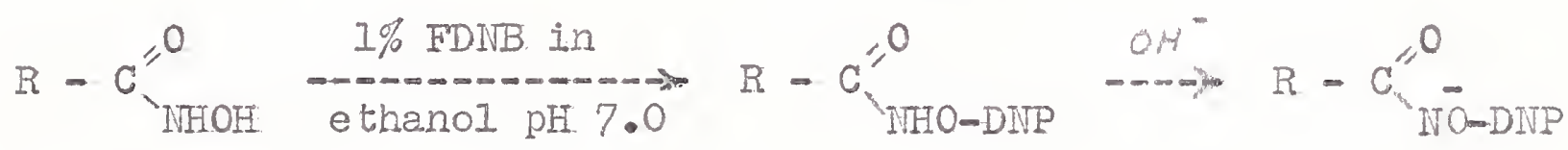

heat

$\rightarrow-\mathrm{R}-\mathrm{N}=\mathrm{C}=\mathrm{O}+\mathrm{DNPO}^{-}-\underset{\mathrm{H}_{2} \mathrm{O}}{\mathrm{O}} \mathrm{RNH} 2+\mathrm{CO}_{2}$

The alpha-Iinked glutamic acid yields alpha,gama-diaminobutyric acid after acid hydrolysis. The gamma-linked glutamic unit has a somewhat different fate, for each of these peptide bonds yields two molecules of ammonia, one from hydrolysis of the amine during Iossen rearrangement and another from subsequent acid hydrolysis of a C-terminal amide fragment, resulting in the appearance of succinic semialdehyde as the gamma rearrangement product.

$$
\begin{aligned}
& \mathrm{R}=\mathrm{C}_{\mathrm{NHH}}^{\mathrm{N}}-\mathrm{CH}-\mathrm{CH}_{2}-\mathrm{CH}_{2}-\mathrm{C}_{\mathrm{NHH}}^{\mathrm{O}}-\mathrm{O} \\
& \text { il }+\mathrm{CO}_{2}+ \\
& 0 \\
& \mathrm{O}=\mathrm{CH}-\mathrm{CH}_{2}-\mathrm{CH}_{2}-\mathrm{CO}-\mathrm{NHR}^{\mathrm{I}}
\end{aligned}
$$

Succinic semialdehyde

Fig. 3. Conversion of the gamma- and alpha-glutamic acid residues of gelatin to the hydroxamate, hydroxamate ester and Lossen rearrangement products. 



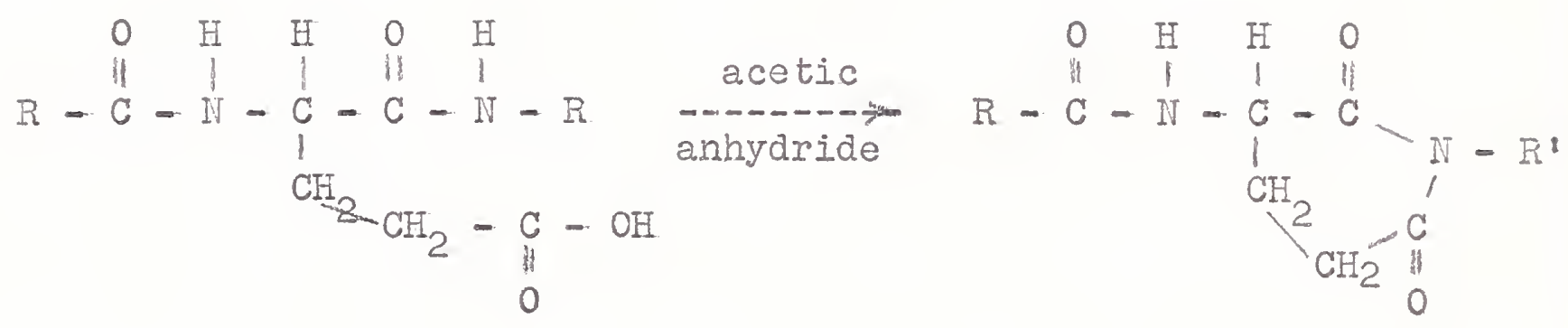

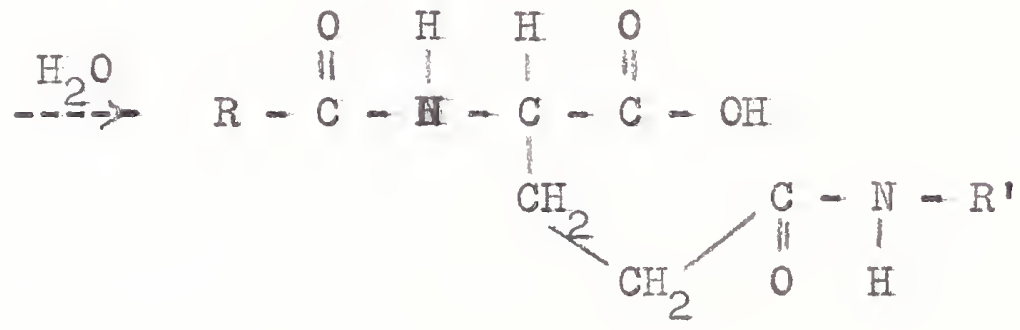

Fig. 4. Method of possible interconversion of alpha- and gamma-glutamyl peptide bonds in the presence of a dehydrating agent. 
1 $-\quad \ldots=$ 
of aspartic acid which disappeared during Lossen rearrangement ( 13 residues per 1000) and the number of molecules of diaminopropionic acid which appeared ( 8.8 residues per 1000). However, the alpha,gamma-diaminobutyric acid recovered accounted for only $21 \%$ of the glutamic residues lost during rearrangement. They reasoned that, in the absence of theoretical contraindications, if interconversion of alpha- and gamma-bonds took place, then it should occur to an equal extent with both alpha-glutamyl and alpha-aspartyl linkages. On the basis of this reasoning they felt that some gama-glutamy peptide links existed in the original collagen.

Franzblau (15), in order to avoid conditions which could promote intermediate imide formation and possible alpha to gama interchange and also to prevent hydroxylaminolysis. of the intramolecular ester cross linkages (Gallop, Seirter, and Meilman (16)), performed a direct conversion by hydroxy Iamine hydrochloride of free carboxyl groups to hydroxamic acids by carrying out the reaction in aqueous, mildly acidic medium containing I-cyclohexyl-3-(2-morpholinyl-(4)-ethyl)carbodimide metho-p-tolueme sulfonate, a water soluble carbodiimde described by Sheehan and Hlavka (17). Franzblau treated the hydroxamate derivative in the same manner 



\section{Table I*}

Products identified after Lossen rearrangement of the dinitropheny l hydroxamate derivative of gelatin derived from icthiocol as compared with a suitable control.

(Expressed as residues per 1000 residues)

\begin{tabular}{|c|c|c|c|}
\hline Compound & Control gelatin & $\begin{array}{l}\text { DNP-Hyaroxamate } \\
\text { Gelatin after } \\
\text { Rearrangement }\end{array}$ & Difference \\
\hline Glutamic acid & 71.4 & 4.6 .0 & -25.4 \\
\hline $\begin{array}{l}\text { alpha, gamma- } \\
\text { Diaminobutyric } \\
\text { acid }\end{array}$ & 0 & 4.3 & $4 \cdot 3$ \\
\hline $\begin{array}{l}\text { Succinic } \\
\text { semialdehyde }\end{array}$ & 0 & 22.0 & +22.0 \\
\hline Ammonia & 42.0 & 78.0 & +36.0 \\
\hline Aspartic acid & 45.8 & 39.6 & -6.2 \\
\hline $\begin{array}{l}\text { alpha, beta-Di- } \\
\text { aminopropionic } \\
\text { acid }\end{array}$ & 0 & 5.0 & +5.0 \\
\hline Dinitrophenol** & 0 & 31.0 & $+3 I .0$ \\
\hline
\end{tabular}

* Franzblau, op. cit., p. 76 .

** Each mole of dinitropheny Ihydroxamate which undergoes rearrangement yields one mole of dinitrophenol. 



\section{(14)}

as Gallop et al. except that the dinitrophenyl derivative of the hydroxamate was formed at pH 8.0 instead of pH 7.0. In this work the succinic semialdehyde was quantitated along with the other rearrangement products and with the amino acids obtained after acid hydrolysis of the rearranged gelatin (Table I). It is evident from Table I that per 1000 residues, 25 residues of glutamic acid were lost with rearrangement and 4.3 residues of alpha, gamma-diaminobutyric acid were recovered. If we are to assume that the rest of the unrecovered glutamic acid, (about 20 residues), was present as gamma-linked glutamic acid, then 40 residues of ammonia and 20 residues of succinic semialdehyde should be found per 1000 residues. In fact 36 molecules of ammonia. beyond those present in the control gelatin and 22 molecules of succinic semialdehyde were recovered. Therefore Franzblau concluded that at least 20 residues of glutamic acid per 1000 residues of total amino acids in collagen are in gamma-glutamyl linkage. The failure of roughly half of the glutamate residues: to be converted to hydroxamates does not affect Franzblau's quantitative statement; because he dernonstrated in synthetic polypeptide experiments that the unconverted glutamic acid residues were in alpha-Iinkage. This conclusion was further supported by the fact that this 

investigator had demonstrated the absence of alpha, garnmacarboxyl interchange when either alpha- or gamma-polyglutamic acid was subjected to an identical procedure. If a similar interpretation is applied to the aspartic acid residues then these must necessarily be alpha-linked.

In addition to the above results, obtained with gelatin prepared from icthyocol, Franzblau also carried out the same procedure with gelatin derived from cali-skin collagen. In this case, however, no quantitative estimation of the amount of succinic semialdehyde was carried out, although its presence was verified by chromatography

In conjunction with some investigations being conducted in this laboratory in which a chick embryo system is being used to study the mechanism of formation of hydroxyproline from proline in the process of collagen synthesis, it was felt that it would be interesing to employ the same system in an investigation of the gamma-glutamyl bond. This dissertation will be concermed with the identification and measurement of gama-linked glutamic acid in chick embryo collagen and with the establishment of an in vivo prepara.tion in which its forration may be studied. 



\section{Materials}

Bovine Achilles tendon collagen was purchased from the Worthington Biochemical Corp., Freehold, New Jersey. It had been purified by the method of Einbinder and Schubert (18).

Medium A was prepared according to Iittlefield and Keller (19) and contained $0.25 \mathrm{M}$ sucrose, $0.025 \mathrm{M} \mathrm{KCl}, 0.005 \mathrm{M}$ $\mathrm{MgCl}_{2}$, and $0.05 \mathrm{M}$ Tris buffer, pH 7.6.

Sephadex-G-25 was obtained from Pharmacia, Uppsula, Sweden. Dowex AG 50W-X8, 200-400 mesh, Hydrogen form, was purchased from the California Corporation for Biochemical Re search, Ios Angeles, California.

Silica gel G (according to Stahl) was purchased from Brinkmann Instruments Inc., Great Neck, New York.

I-cyclohexyl-3-(2-morpholinyl-(4)-e.thyl)-carboditmide metho-p-toluene sulfonate. was purchased from the Aldrich ChemicaI Co, Milwaukee, Wisconsin. This compound will be referred to as Wsc throughout the remainder of this paper. This is a water-soluble carbodilmide which Franzblau (15) found could promote, in an aqueous, slightly acid= ic medium, the direct conversion by hydroxylamine hydrochloride of free carboxyl to hydroxarnic acid groups. When applied to the gelatin from icthyocol, Franzblau found that this method resulted in the conversion of 40 to $50 \%$ of the 

free carboxyl groups to hydroxamic acids in 2 hours. A separate experiment conducted for 19 hours resulted in approximately $65 \%$ conversion to hydroxamic acid groups. Acethydroxamic acid was prepared by a modirication of the synthesis of benzohydroxamic acid according to Blatt (20). Separate solutions of $46.7 \mathrm{~g}$ of hydroxylamine hydrochloride in $240 \mathrm{mI}$ of methanol and $56.1 \mathrm{~g}$. Of $\mathrm{KOH}$ in 140 ml. of methanol were prepared at the boiling point of the solvent. Both solutions were cooled to $30-40^{\circ} \mathrm{C}$, and the alkali solution was added to the hydroxylamine solution in an ice bath. This mixture was allowed to stand in an ice bath for 5 min., and the KCl which formed was filtered orf on a Buchner funnel. 4I. g. of ethyl acetate were added with stirring and the mixture was allowed to stand at room temperature for 6 hours. This solution was evaporated and an oil appeared which was neutralized to $\mathrm{pH}$ 7.0 with $\mathrm{HCl}$. The neutralized oil was dissolved in hot ethyl acetate. The hot solution was allowed to cool slowly to $4^{\circ} \mathrm{C}$. The acethydroxamic acid readily crystallized out on cooling. It was then filtered and stored in a dessicator in vacuo. The purity of the compound was verified by a melting point determination。

Succinic semialdehyde-2,4-dinitrophenylhydrazone was. 

prepared by the method of Hendler and Anfinsen (21). I47 $\mathrm{mg}$ of glutamic acid were dissolved in $10 \mathrm{ml}$. of warm 0.1 IN NaOH. Nitrogen was bubbled through the solution for a few minutes and $290 \mathrm{mg}$. of chloramine-T (sodio-p-toluenesulfochloramine) were added. The mixture was placed in a water bath at $50^{\circ} \mathrm{C}$. for $15 \mathrm{~min}$, cooled in ice, centrifuged and the insoluble p-toluenesulfonamide was discarded. To the supernatant solution containing succinic semialdehyde were added $28 \mathrm{ml}$. of $0.8 \% 2,4$-dinitrophenylhydrazine in 2 I HCI. The suspension was filtered, and dried in vacuo. Purification of the compound was carried out by dissolving it in alcohol at $35^{\circ} \mathrm{Cog}$ adding water at room temperature, and cooling in a dry ice-acetone mixture. The succinic semialdehyde-2, 4-dinitrophenylhydrazone crystallized out on cooling; it was centrifuged, the supernatant was decanted, and the compound dried in vacuo. The M.P. of the prepared sample was $197-199^{\circ} \mathrm{C} \cdot$; the reported authentic M.P. is $199-201^{\circ} \mathrm{C}$. 

Methods.

Preparation of cell-free enzyme fractions - 15 7-day old White Leghorn chick embryos weighing $0.7 \mathrm{~g}$. each were blended in three fourths of their. volume of Medium A containing 10 umoles/ml of mercaptoethanol in a Servall omniMix homogenizer for 15 seconds. The resulting suspension was spun for 10 minutes at $12,500 \mathrm{r} \cdot \mathrm{p} \cdot \mathrm{m}$. at $3^{\circ} \mathrm{C}$. In the 40 rotor of the spinco Model I centrifuge. The supernatant from this centrifugation was centrifuged as above for 20 min. at $15,000 \mathrm{r} \cdot \mathrm{p} \cdot \mathrm{m}$. The supernatant from this second centrifugation constituted the S-15 fraction. The S-15 fraction was centrifuged for 90 minutes at 40,000 r.p.m. $(105 \mathrm{Xg})$. The sediment from this $\mathrm{S}-105$ fraction was homogenized in $15 \%$ of the volume of the $\mathbf{S}-105$ fraction of Medium A with added mercaptoethanol as per above and this suspension constituted the microsomal fraction. To prepare the pH 5 enzyme system, the $5-105$ supernatant was brought to pH 5.2. with 1 II acetic acid, centrifuged for 15 minutes a.t. 20,000 r.p.m., and the sediment was taken up in $15 \%$ of the S-105 volume of Medium A with added mercaptoethanol. Preparation of whole-cell incubations - The chick eggs were shelled, the embryos were cut up with scissors, and minced in a loose-fitting glass homogenizer at slow speed. 

with either 2.5 or $3.0 \mathrm{mI}$ of cold Krebs Ringer's phosphate soDution per gram of tissue. Although a microscopic examination of the resultant suspension was not made, it was felt that this procedure yielded a predominanty whole-cell preparation.

Incubations, were terminated by adding sufficient coId I0\% or $20 \% \mathrm{TCA}^{1}$ to make a Iinal concentration of $5 \%$ In the case of the whole-cell preparations, the incubations were mixed thoroughly in a Waring blender: (10 - 20 seconds) after precipitation of the protein.

Extraction of the collagen as gelatin - Collagen was separated from cold TCA-soluble material by washing the first precipitate 4 times with cold $5 \%$ TCA. The collagen was then solubilized in the gelatin form by heating in $5 \%$ TCA for 70 minutes at $90^{\circ} \mathrm{C}$. after the method of Peterkofsizy and Udenfriend (22)。B B this method these authors were consistenty able to remove approximateIy $85 \%$ of the hydroxyproline from the precipitate. The hot-TCA extracts were extracted 4 times. with anhydrous ether in order to remove the trichloroacetic acid.

Purification of hot TCA-insoluble protein and determination of specific activity - $4 \mathrm{ml}$ of $0.4 \mathrm{NITOF}$ and

1. The abbreviation used is: TCA, trichIoroacetic acid. 
1 
$0.5 \mathrm{mI}$ of a solution of unlabeled glutamate ( $10 \mathrm{mg} / \mathrm{ml}$ ) were added to the hot TCA-insoluble proteins and the solutions were heated at $60^{\circ}$ for 2 minutes. $1.0 \mathrm{mI}$ of $50 \%$ TCA was added to precipitate the proteins and the vessels were cooled in the reIrigerator for 15 minutes. The vesseIs were centrifuged and the precipitated protein was washed two times with $95 \%$ ethanol and once with ether-ethanol solution ( $1: 3$ by volume). The protein was then heated to $70^{\circ} \mathrm{C}$. For 2. minutes, washed once with anhydrous ether and dried. The dried purified protein was then dissolved in $1.0 \mathrm{mI}$ of anhydrous formic acid and the activities of weighed amounts were determined. Separation of the hot TCA-Soluble fraction into a small molecular weight and a macromolecular fraction The hot-TCA extracts were evaporated to a volume of 2.0 $\mathrm{ml}$ and placed on the top of columns of Sephadex G-25, $16 \mathrm{~cm} \mathrm{X} 1.5 \mathrm{~cm}$, containing $9.3 \mathrm{~g}$ dry weight of gel with a. water regain or $2.4: \mathrm{g}_{2} \mathrm{H} / \mathrm{g}$ dry gel. The columns were eluted with $100 \mathrm{mI}$ 0.2. M ammonium formate. $2 \mathrm{mI}$ fractions were collected and alkaline hydrolysis according to the method of Hirs, Stein, and Moore (23) was carried out on exch of the first 20 fractions eluted. 1.0 m of 2.5 IN $\mathrm{NaOH}$ was added to $0.13 \mathrm{mI}$ aliquots of each 2.0 m I fraction to be hydrolyzed. The tubes were placed 

in a $90^{\circ} \mathrm{C}$. bath for 2.5 hours, during which time the contents evaporated to a volume of about 0.2 to $0.4 \mathrm{~m}$. The hydrolyzed fractions were then analyzed by a modified ninhydrin method. After $1.0 \mathrm{ml}$ of $30 \%$ (by volume) acetic acid was added to each of the cooled tubes, in order to bring the solutions to about pH $5,0.5$ mI of ninhydrin reagent (prepared according to the method of Moore and Stein (24)) was added and the tubes were covered and placed in a boiling water bath for 15 minutes. After. cooling, 2.5 mI of I:I. ( $\mathrm{v} / \mathrm{t})$ ethanol-water diIuent were added to each tube and the absorbancy was read at $570 \mathrm{mu}$ against an ammomium formate standard. By this method the fractions containing: the small molecular compounds: were abie: to be identified by their respective ninbydrin reactive peaks. The macromolecular components came off the columns between about $11.0 \mathrm{ml}$ and $16.0 \mathrm{mI}$. The smaller molecules started to be eluted at between 21.0 and 24.0 mI. The sespective pooled macromolecular and smaII molecular fractions were Iyophilized. The residue was dissolved in $1.0 \mathrm{ml}$ of distilled water, and $0.1 \mathrm{ml}$ and 0.2 mI samples were plated and counted.

AII radioactivity was measured with a Nuclear-chicago Geiger counter, ModeI \# $181 \mathrm{~B}$.

Unless otherwise mentioned, acid hydrolysis was carried 

out by making the solution of sample 6 II with respect to HCI and heating in a pressure cooker at approximately $15 \mathrm{Ibs} . / \mathrm{sq}$. in., for three hours.

Preparation of the poIyhydroxamic acid derivative of gelatin - This was carried out according to the method employed by Franzblau (I5). $350 \mathrm{mg}$ of hydroxylamine hydrochloride and $846 \mathrm{mg}$ WSC were added per ea.ch $5.0 \mathrm{mI}$ of aqueous gelatin solution (after evaporation of the gelatin solutions to convenient volumes). The resultant, solutions were allowed to stand at roon temperature, with occasional stirring, for 2.5 hours in the case of the bovine collagen and 2.0 hours in the chick embryo experiments. After standing, the protein was precipitated with cold acetone (care must be talsen here since as much as one third of the collagen may not be precipitated), washed with ether and dried in vacuo. The dry hydroxamate derivative was then weighed and dissolved in varying volumes of warm distilled water as s.tated in the record of the individual experiments. The hydroxamic acid was either assayed by the procedure described. a.t the end of the methods section of this paper or its presience was verified by placing a drop of the aqueous hydroxamate solution on a small quantity of ferric chloride in a test tube and observing the evolution of a wine-red. color (the red reaction is specific for hydroxamic acid 

groups since: hydroxylamine itself does not yield color). Dinitrophenylation and Lossen rearrangement of the gelatin polyhydroxamate derivative - The method employed was that of Seifter, Gallop at al (25) as modified by FranzbIau (15). The pH of the aqueous hydroxamate solution was adjusted to 8.0 with $\mathrm{Na} . \mathrm{OH}$ and an equal volume of $1 \%$ FDIN $(v / v)$ in ethanol was added with constant stirring by means of a magnetic bar. The pI of the mixture was measured with a pH meter and the reaction was maintained at pH 8.0 by constant toltration with INaOH, until the pH was stabie (approximately 5.0 minutes). The solution containing the hydroxamate-DIN derivative was extracted twice with anhydrous ther and once with petroleum ether in order to extract the excess fluorodinitrobenzene. The extracted solution was made 0.1 N with respect to $\mathrm{NaOH}$ and heated for 2 minutes at $100^{\circ} \mathrm{C}$. to promate Iossen rearrangement.

Formation and extracition of the 2,4-dinitrophenylhydrazone derivatives; - To either one half on all of the hydrolysate an equal volume of $0.8 \% 2,4-d i n i t r o p h e n y I-$ hydrazine in 2 II HCI was added, and the resulting solution containing the 2,4-dinitrophenyIhydrazones was evaporated to a convenient volume in a flash evaporator (the temperature of the evaporating bath was kept below 


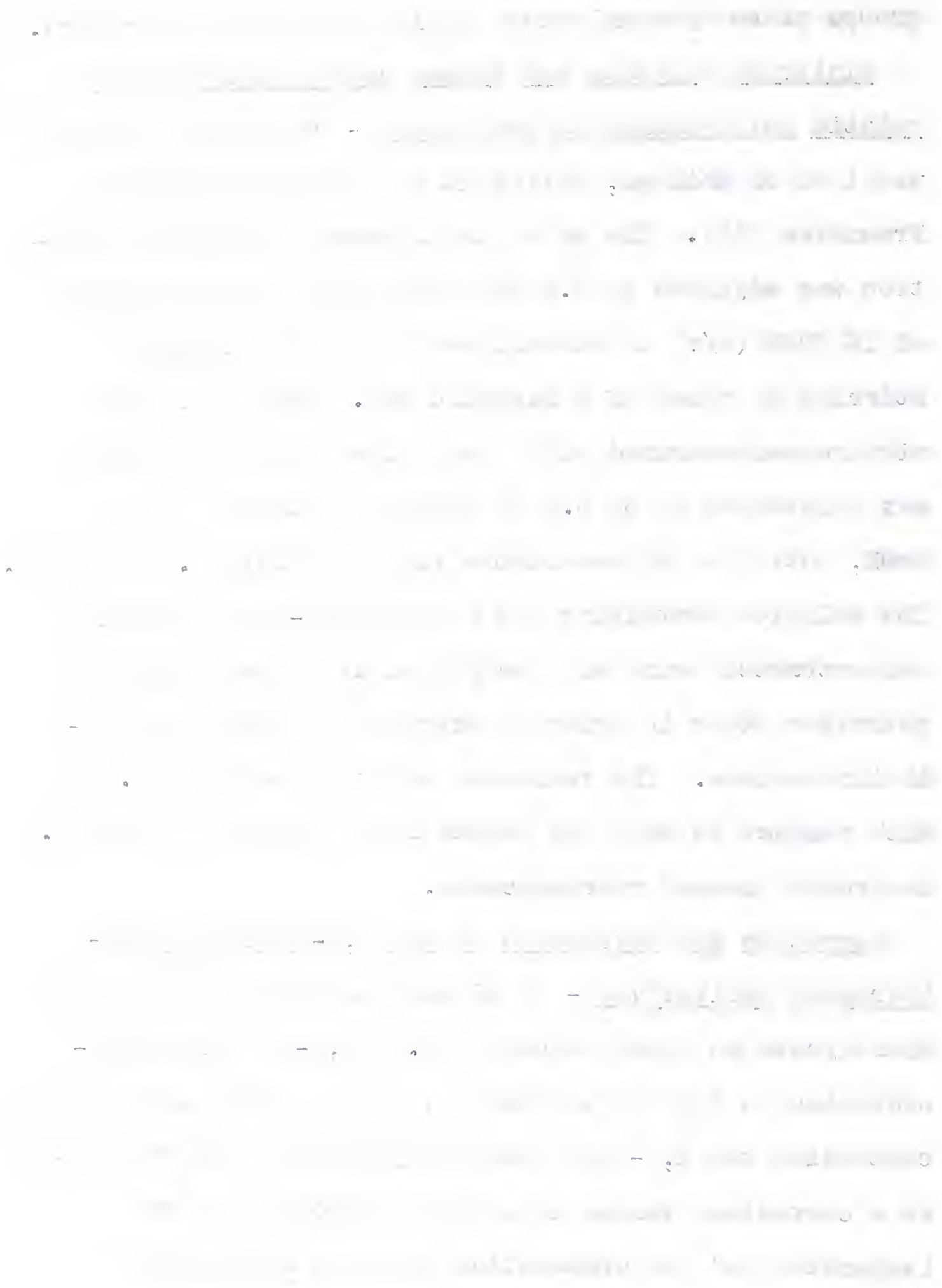


$\left.35^{\circ} \mathrm{C.}\right)$. The concentrated solution was extracted 2 or 3 times with ethyl acetate and the extracts were: combined. The ethyl acetate solution was extracted with 0.1 M borate buffer, pH 9.0; until at Ieast 2 extractions had been performed with the resulting borate solution being basic as tested by pH paper. The borate solutions were pooled and scidified with 2 II HCl and extracted into ethyl acetate. Where mentioned, this final ethyl acetate extract was further purified by electrophoresing a known volume of Whatman 3 MM paper with a sample of the standard succinic semialdehyde-2,4-dinitropheny Ihydrazone at pH 8.6 in sodium barbital buffer ( $5 \mathrm{~g}$ sodium barbital, 3.258 sodium acetate trihydrate, and $34.2 \mathrm{mI}$ of $0.1 \mathrm{II}$ ICI brought to 1 liter with distilled water) at I200 v across $59 \mathrm{~cm}$ for approximately 2 hours. The band correspont ing to the marker was completely eluted with a known volume of 0.1. M borate buffer (pH 9.0).

Thin layer chromatography - It was found that paper chromatography as employed by both Gallop (14) and Franzblau. (15) was totally inadequate in this work, as: both the bovine and the avian experiments; yielded severa. 2,4mainitrophenylhydrazone derivatives which acted similarly on electrophoresis and one of these also migrated very cIose to the uniznown on chromatography After trying without success several methods of paper chromatography with a 
a. 
great variety of solvents recomended for separation of 2,4-dinitrophenyIhydrazone derivatives, it was found that a high degree of eesolution with excellent separation of the components was attained by thin layer chromatography with silica gel. The 2,4-dinitrophenylhydrazones were developed by spraying with alcoholic $\mathrm{KOH}(3.5 \mathrm{mI} 15 \mathrm{~N} \mathrm{KOH}$ to $20 \mathrm{mI}$ with ethanol)。 GIass plates were spread with silica gel G, $0.5 \mathrm{~mm}$ in thickness, by conventional methods. These were allowed to stand at room temperature for a few minutes and then dried in an oven at $110^{\circ} \mathrm{C}$. The samples to be: chronatographed were extracted from the borate buffer into the ethyl acetate as: described above and a measured volume of the ethyl acetate was placed on the silica covered glass plates in a connected series of very small drops thus forming a line. Although it may not be necessary, the chromatograms: were run in the dark. The solvent used for separation wa: tertiary amy alcohol-ethanol-water. (5:1:4, top layer). The band corresponding to succinic semialdehyde-2,4-dinitrophenylhydrazone was scraped off the plate into a test tube and eluted: into a known volume of 0.1 Mborate buffer, $\mathrm{pH} 9.0 .1$ part.

I. It is interesting to note that in order to extract the succinic semialdehyde-2,4-dinitrophenylhydrazone from the silica geI with ethyl acetate, a drop of HCl must be added, a fact that suggests: that, for an unknown reason, the carboxyl. group is converted from the acid to the salt form during the process of chromatography. In any case, complete elution is readily attained with the borate buffer: 

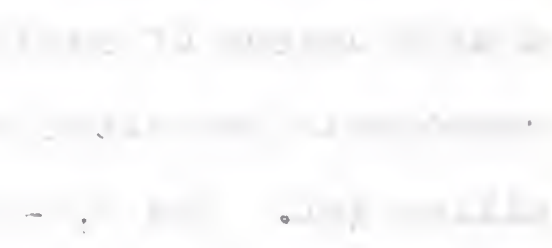
of this solution was assayed and part extracted into ethyl aceta.te and chromatographed with a sample: of the authentic succinic senialdehyde-2, 4-dinitrophenylhydrazone (the authentic sample aad also been purified by chromatography in the tertiary amyl alcohol-ethanol-water system, eluted into borate solution, and extracted with ethyl acetate prior to its use as a standard marker) in the tertiary amyl a.Icohol-ethanol-water (5:I:4:) solvent and also in a solvent of normal butanol saturated with water. In placing the experimental solution on the origin of the chromatogram, a line $3 \mathrm{~cm}$ Iong was made. The authentic marker was then placed in a similar series of dots forming a line $3 \mathrm{~cm}$ in length such that $1.5 \mathrm{~cm}$ of the marker was superimposed on the terminal $1.5 \mathrm{~cm}$ of the experimental line and $1.5 \mathrm{~cm}$ was free. Fajlure of the experimental sample to separate from the standard compound in two solvent systems was accepted as proof of identity.

Desalting and isolation of amino acids. The aqueous phase remaining after extraction of the hydrolusate with ethyl acetate was evaporated to a volume of two $\mathrm{ml}$ and placed on top of a $20 \mathrm{ml}$ column containing Dower $50-8 \mathrm{X}$ ( $\mathrm{H}^{+}$). The column was rinoed with 80 to $100 \mathrm{ml}$ of distilled water and the amino acids. were eluted with $50 \mathrm{mI}$ of $2 . \mathrm{N}_{4} \mathrm{NH}_{4}$. The eluate was evaporated to $5.0 \mathrm{ml}$ and known volumes. 

were placed on Whatman 3 Maper and electrophoresed. in pH 6.0 pyridine acetate buffer ( $100 \mathrm{ml}$ pyridine and $10 \mathrm{ml}$ glacial acetic acid brought to I liter with distilled water) at 2,000 volts across $47 \mathrm{~cm}$ for 1 hour 15 minutes. Alpha, gamma-diaminobutyric acid was identified by its similar migration to a marker of the commercially prepared compound and by its characteristic red-brown staining reaction when the experinental marker section of the paper was sprayed with $0.5 \%$ ninhydrin in acetone. The area identified as alpha, gamma-diaminobutyric acid and those of the other amino acids desired were cut out and eiluted from the electrophorogram with known volume of water. These solutions were then assayed, and, when pertinent, their radioactivity was assesed.

Assay procedures - Hydroxanic acid assay was carried out according to the ferric perchlorate method of seifter, Gallop et: al (25). The solution ( $\mathrm{mI}$ ) containing 0.2 to. 2.0 umoIes of hydroxamic acid was mixed with 2 mi of ferric perchlorate reagent (prepared by dissolving 0.8 g of pure iron wire in $10 \mathrm{ml}$ of warm $60 \%$ perchloric acid and bringing the solution to $100 \mathrm{ml}$ with etranol) diluted 1:I with distilled water. Arter 5. minutes it was read at $505 \mathrm{~m}$ against a reagent blank. A standard curve was simultaneousily prepared from a sitandard (2 גmoles/mI) 

solution of acethydroxamic acid. This method measures only hydroxamic acids and gives no color from hydroxylamine. OpticaI density readings were performed with a Zeiss: Spectrophotometer.

GIutamic acid and alpha, gamma-diaminobutyric acid were measured by a modified ninhydrin procedure as follows: Preparation of Ninhdrin reagent; $40 \mathrm{mg}$ of Sncl2 were dissolved in $25.0 \mathrm{mI}$ pH 5.0 acetate buffer and $0.667 \mathrm{~g}$ of ninhydrin were dissolved in $25.0 \mathrm{ml}$ of methyl cellosolve (monomethyl ether of ethylene gIycol). Just before the assay $8.3 \mathrm{ml}$ of the $\mathrm{SnCl}_{2}$ solution were mixed with all. of the ninhydrin solution. Assay: to $0.5 \mathrm{ml}$ samples, $0.5 \mathrm{mI}$ pH 5.0 acetate buffer and $1.0 \mathrm{ml}$ ninhydrin reagent were added in test tubes. Which bad been rinsed several times with distilled weter and dried. The solutions were mixed well, the test tubes were capped with glass marbles and they were placed in a covered boiling water bath por 15 minutes. At the end of this period they were cooled to room temperature in ice water and the volume was brought to $5.0 \mathrm{mI}$ with $95 \%$ ethanow. The solutions were mixed weII and the O.D. Was read at $570 \mathrm{~m} \mu$ against a reagent blank. Standard curves (0.05-0.50 umoles) of glutamic acid and alpha, gammadiaminobutyric acid were carried out each time the assay was: done: 

Hydroxyproline was measured according to the method of Newman \& Logan (26) as modified by Leach (27) at I/IO volune. To the sample brought to $0.1 \mathrm{ml}$ with water was added. O.I $\mathrm{mI}$ of $2.5 \mathrm{~N}$ IraOH. The tubes were placed in $2.40^{\circ} \mathrm{C}$. water bath, and when the contents, of the tubes reached $40^{\circ}$ C. (3-5 minutes), $0 . \mathrm{Im}$ of $6 \% \mathrm{H}_{2} \mathrm{O}_{2}$ was added and the solution was mixed. After another 10 minutes in the bath, the solutions were cooled and $0.4 \mathrm{mI}$ of $3 \mathrm{~N} \mathrm{H}_{2} \mathrm{SO}_{4}$ and $0.2 \mathrm{mI}$ of 5\% p-dimethylaminobenzaldehyde in n-propanol were added. The tubes were placed in a $70^{\circ} \mathrm{C}$. bath for 20 minutes, cooled. and the 0.D. was read at $555 \mathrm{m \mu}$. Three different concentrations of each unknown solution were assayed and a standard curve $(0.01-0.05$ moles) was constructed with each assay.

Proline was measured by the method of Chinard (28). To I.0 mI of the sample to be assayed, $1.0 \mathrm{ml}$ of glacial acetic acid and $1.0 \mathrm{mI}$ of ninhydrin reagent were added (each $\mathrm{mI}$ of reagent contained $0.4 \mathrm{mI}$ of $6 \mathrm{~N} \mathrm{H}_{3} \mathrm{PO}_{4}$ and 0.6 $\mathrm{mI}$ of glacial acetic acid; $25 \mathrm{mg}$ of ninhydrin were added per ml of this acid mixture and the mixture was heated to about $70^{\circ} \mathrm{C}$. to insure solution of the ninhydrin). The tribes were capped and heated at $100^{\circ} \mathrm{C}$. for I hour, after which time they were cooled to room temperature, and brought to a volume of $5.0 \mathrm{ml}$ with glacial acetic acid. The O.D. was read a.t $515 \mathrm{~m} \mu$ against a reagent blank. A standard 



\section{(31)}

curve (0.02-0.2 umoles) was constructed and 3 different. concentrations of each unknown solution were assayed. Succinic semialdehyde was assayed according to the prom cedure described by Waelsch (29). The solution to be assayed was brought to $5.0 \mathrm{mI}$ in borate buffer $\mathrm{pH} 9.0$, and mixed with 2 mI of alcoholic KOH $(3.5 \mathrm{mI}$ of $15 \mathrm{~N} \mathrm{KOH} \mathrm{made}$ to $20 \mathrm{ml}$. with absolute ethanol). After mixing the tube was placed in a water bath at $25^{\circ}$ C. Exactly 2 minutes after addition of the alkali the absorbancy was measured. at $420 \mathrm{~m} \mu$ against a blank containing $5 \mathrm{ml}$ of borate buffer and $2 \mathrm{ml}$ of alcoholic KOH. A standard curve was simultaneously prepared from a standard solution ( 0.1 umoles/ml) of the authentic compound in borate buffer. 

Results.

I. Incorporation of $\mathrm{C}^{14}$-8utamic acid into the collagencontaining hot trichloroacetic acid-extractable fraction by a cell-free system from Z-day chick embryos.

Cell-free enzyme fractions were prepared from 15 7-day old. White Leghorn chick embryos and incubated as described in Table II. The incubations were terminated by precipitating the protein with cold. TCA. The precipitated protein was then washed, 20 jumoles of unlabeled glutamic acid carrier were added to each vessel, and the protein was extracted for 80 minutes with hot TCA. The hot TCA-extracts were extracted with ether, and their radioactivity was measured. That protein which was not soluble in hot TCA was purified and a determination of its specific activity was made。 The gelatin-containing hot TCA-extracts were separated into small molecular weight and macromolecular fractions, and the radioactivity or each was determined (Table III).

From the data presented in Table. II it is evident that the cell-iree 7-day old chick embryo incubation using a. pH 5 precipitated enzyme system in conjunction with the microsomaI fraction, incorporated $\mathrm{C}^{1^{4}}$-glutamic acid into the collagen-containing hot TCA-extractable protein fraction. The amount of incorporation, however, was small. The spec- 

Table II

Incorporation of Cl4-glutamic acid into the collagen-

containing hot rCA-extractable fraction by a cell-free

system from 7-day chick embryos and specific activity

of the purified non-collagenous protein.

All incubations contained in a final volume of $6.0 \mathrm{ml}$ : $0.30 \mathrm{mI}$. Tris buffer 1.0 M, pH 7.7; $0.12 \mathrm{mI}$ ATP, 50 jumoles/mI; $0.12 \mathrm{ml}$ magnesium ace ta.te $0.3 \mathrm{M} ; 0.63 \mathrm{ml} \mathrm{KCl}, 1.0 \mathrm{M} ; 0.12 \mathrm{mI}$ GTP, 2.5 umoles $/ \mathrm{ml} ; 0.24 \mathrm{ml}$ glutathione, $2002 \mathrm{moles} / \mathrm{ml} ; 0.33$ mI sodium phosphoenolpyruvate, $100 \mathrm{pmoles} / \mathrm{ml} ; 0.12 \mathrm{ml}$ pyruvate. kinase, I mg/mi; $0.12 \mathrm{ml}$ ascorbic acid, 50 pmoles/mi; $0.15 \mathrm{mll}$ cysteine, 2 moles/mI; $0.30 \mathrm{ml}$ amino acid mixture; containingI-proline, argenine, lysine, threonine, serine, leucine, phenylalanine, methionine, valine, asparagine, aspartic acic, isoleucine, histidine, tryptophan, alanine, tyrosine, aqgd glycine at a concentration of $1.0 \mathrm{~mole} / \mathrm{ml}$. $6.50 \mathrm{mI}$ of $\mathrm{C}^{1}$ glutamic acid (28uc/unole, $2.24 \times 10^{6} \mathrm{~cm} / \mathrm{ml}$ ) was added to vessels I and2 bafore incubation and to vessel 3 after precipitation of the protein.

The incubation was carried out at $38^{\circ}$ C. for 90 minutes.

\begin{tabular}{|c|c|c|}
\hline VesseI \# & Contents & $\begin{array}{l}\text { collagenous } \\
\text { protein }\end{array}$ \\
\hline
\end{tabular}

Specific

Total

activity of

activity

of non-

collagenous

pH 5 Microsome $S-15$

fraction fraction fraction

(epm/mg)
(pH 5$)$
2
$(S-15)$
I. $20 \mathrm{mI} \quad 1.80 \mathrm{mI}$
$-1290$
100 (pH 5 .
$1.80 \mathrm{mI} \quad 1.20 \mathrm{mI}$
781
36
693
32 


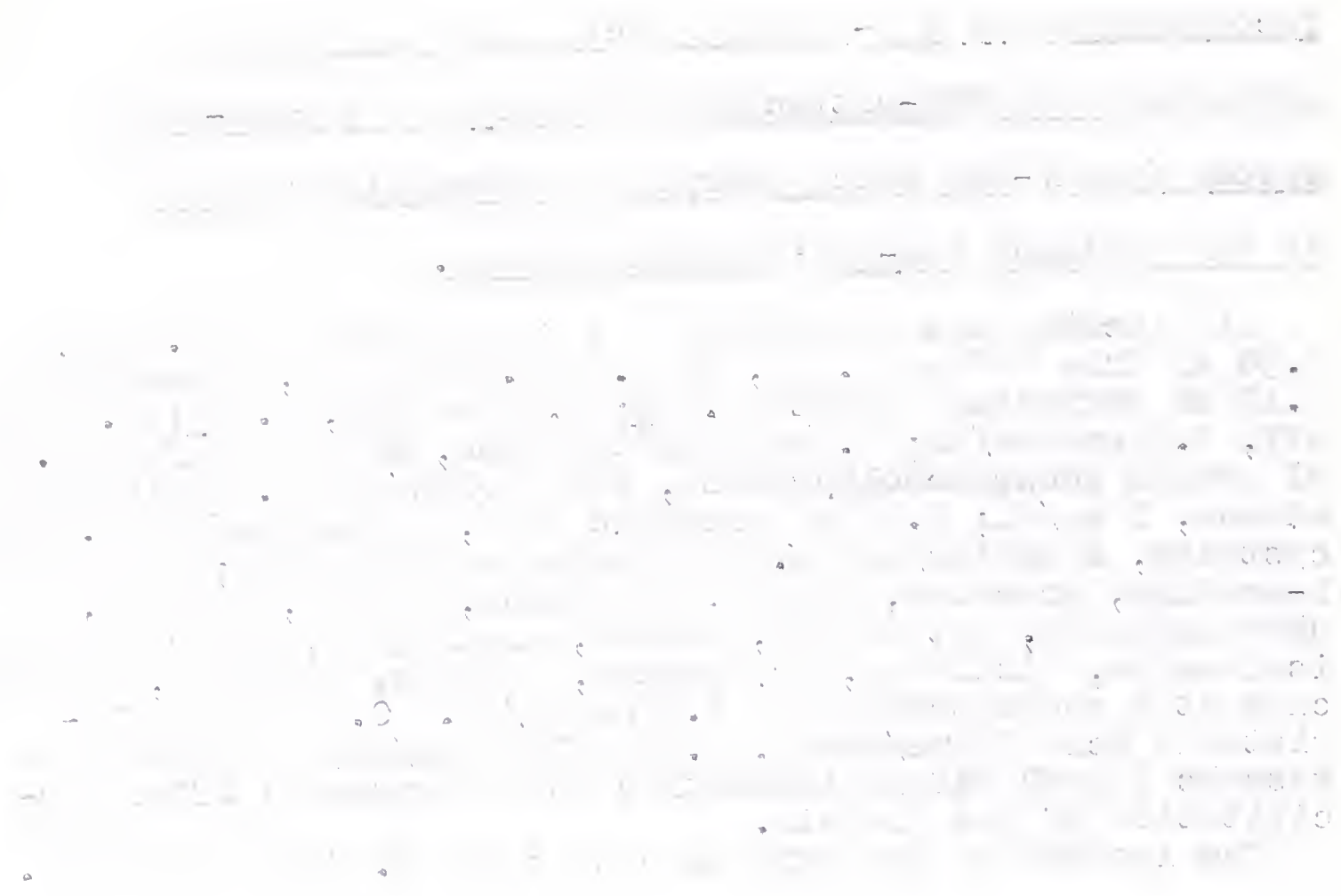


TabIe III

The radioactivity in the macromolecular and smali molecular fractions separated by means: of a Sephadex G-25 column.

\begin{tabular}{|c|c|c|}
\hline Fraction & $\begin{array}{l}\text { Macromolecular } \\
\text { activity } \\
\text { (totaI com) }\end{array}$ & $\begin{array}{l}\text { Small molecular } \\
\text { activity } \\
\text { (total com) }\end{array}$ \\
\hline pH 5 \& Microsomes, & 59 & 219 \\
\hline $\mathrm{S}-15$ \& Microsomes & 104 & 118 \\
\hline pH 5 control & Background & 119 \\
\hline
\end{tabular}


ific activities of the non-collagenous protein fraction verify the fact that the extent of incorporation was not impressive. Due to the low incorporation of the system, it was decided to employ whole-cell systems from minces of embryos in the future.

Only a fraction (about 20\%) of the total hot rCA extract radioactivity was recovered after sephadex fractionation (Table III). Much of the activity recovered was present in the small molecular fractions, but there was some incorporation into macromolecular protein (eg. collagen). In a larger incubation employing $\mathrm{C}^{1^{4}}-$ glutamic acid of a higher specific activity it is expected that a greater incorporation into the macromolecular fraction would take place.

II. Evidence for the presence of gamma-gutamy bonds in a commercially preoared collagen obtained from bovine Achilies tendon.

For the purpose of testing the rearrangement procedure. and the methods of recovery of the rearrangement products, it was decided to submit some commercially prepared collagen to the various manipulations that will be employed with the chick embryo gelatin.

2.0 g of bovine Achilles tendon collagen were suspended in $50 \mathrm{ml}$ of distilled water and atoclaved at $125^{\circ} \mathrm{C}$. for 

3 hours. As some tissue remained at the end of this procedure, 20 additional $\mathrm{ml}$ of distilled water were added to the above solution and it was heated again under the same conditions. The solution was cooled, centrifinged, and the gelatin-containing supernatant was decanted. One half of the gelatin solution was hydrolyzed and served as the unrearranged control. The other half of the gelatin solution was evaporated to $5.0 \mathrm{ml}$ and the polyhydroxamate derivative was formed. The dry gelatin hydroxamate weighed $949.2 \mathrm{mg}$ and was dissolved in $62.5 \mathrm{ml}$ of warm distilled water. There were 781 umoles of hydroxamic acid in the solution submitted to Lossen rearrangement. The polyhydroxamate-DIP derivative was formed, the rearrangement was promoted by heating at alkaline pH, and the solution was hydroIyzed.

The hydrolysates of both the rearranged and the unrearranged gelatins were divided into two equal parts. One half of each hydrolysate was evaporated to $10 \mathrm{ml}, 1.0 \mathrm{ml}$ of this volume was electrophoresed a.t. pH 6.0 without previous desalting, and glutamic acid, alpha, gamma-diaminobutyric acid and hydroxyproline were eluted and assayed.

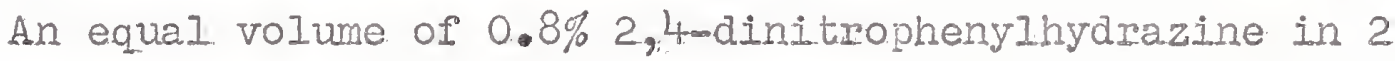
IN HCI was added to the other half of each hydrolysate and the 2,4-dinitrophenylhydrazone derivatives. were extracted 

Analysis of some of the products in the Lossen rearranged. dinitrophenyIhydroxamate derivative of gelatin derived from bovine Achilles tendon as compared with an unrearranged control gelatin.

(Expressed as total number of junoles recovered) Rearranged values a.djusted to hydroxyproline recovered from

Compound. Rearranged Control ControI Difference

Hydroxyproline. 4.67 676 676

Glutamic acid. 284 612

4.1 $-201$ a.lpha,gammadiaminobutyric acid.

Succinic semialdehyde. 

with ethyl acetate. A portion of the final ethyl acetate solution after extraction with borate buffer was chromatographed andthe succinic semialdehyde-2, 4-dinitrophenylhydrazone was identified and assayed. In this case the abowe compound was eluted from the silica gel in $2.0 \mathrm{ml}$ of ethyl acetate to which had been added a drop of: $2 \mathbb{N}$ HCI.

It may be seen from Table. IV that some succinic semialdehyde was present in the hydrolyzed gelatin that had not been rearranged. The loss of glutamic acid in the rearranged as compared to the unrearranged control is not accounted for by the appearance of an equivalent quantity of glutamic acid rearrangement products in the rearranged gelatin. Because of this discrepancy no quantitative statements concerning the amount, of gamma-linked glutamic acid present in the bovine Achilles tendon collagen can be made. It is evident, that Lossen rearrangement of glutamic acid units took place, as wi.tnessed by the appearance of: alpha, gamma-diaminobutyric acid (the alphalinked rearrangement product) in the rearranged gelatin and not in the unrearranged control. The rearranged gelatin also yielded 5.2 times as much succinic semialdehyde (the gamma-linked rearrangement product) as was endogenousiy present in the control. 


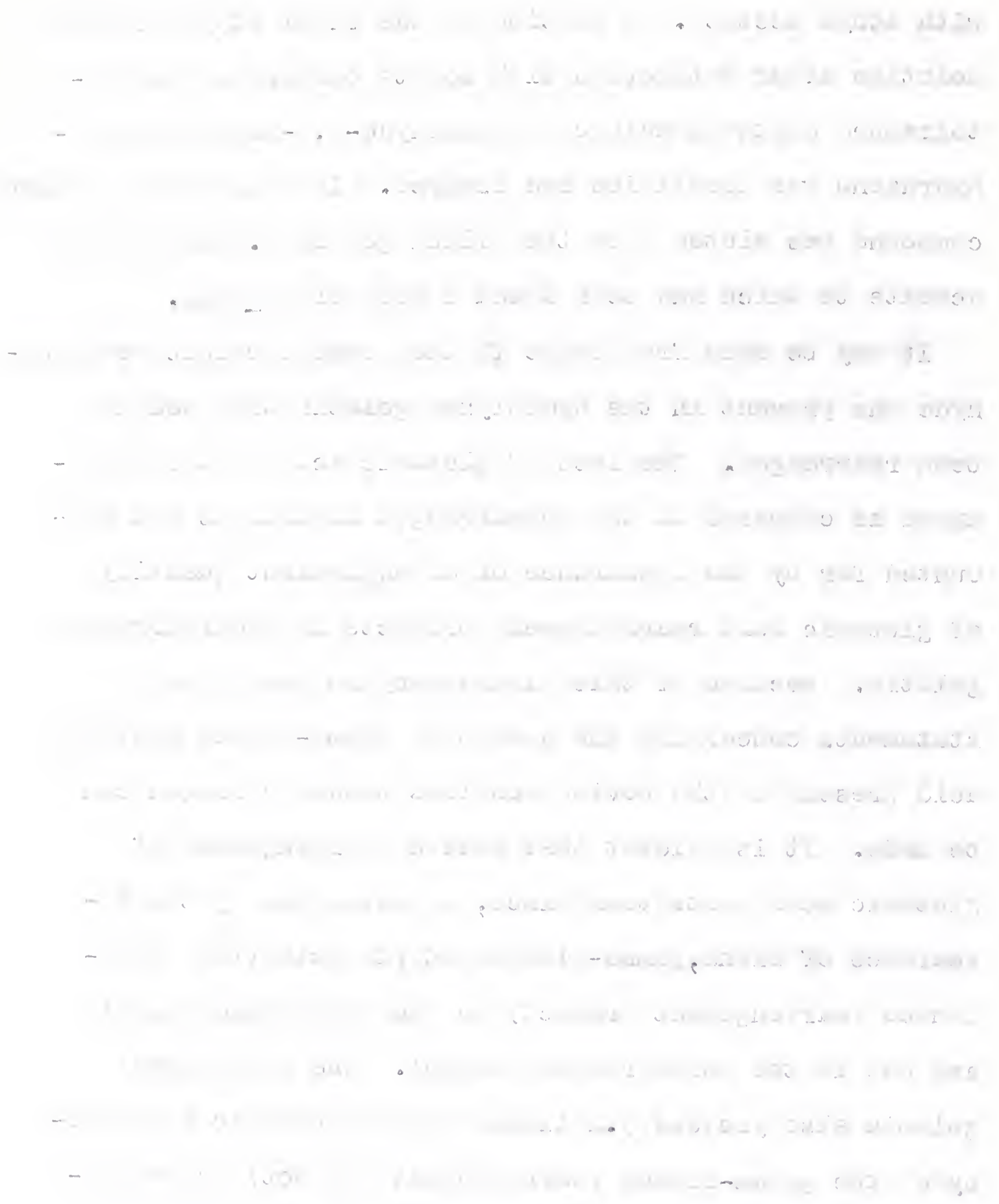

$a$ 
III. The aplication of the Lossen rearrangement to the hot TCA-extractable protein derived from 14 dat old chick erabryos after incubation with $\mathrm{C}^{14}-$ glutamate.

It was decided to do an isotopic experiment with a I4 day old chick whole-cell preparation in order to see if the gamma-linked rearrangement, product could be isolated from this age embryo, and also to see if the preparation would incorporate radioactivity into gamma-linked glutamy units. As this experiment was designed as a quich pilot experiment to indicate where Iuture investigation should. be focused, neither a rearrangement control nor a radioactivity incorporation control. was included.

A whole-cell incubation was prepared by homogenizing 20. I4 day old. White Leghorn chick embryos weighing approyimately $9.9 \mathrm{~g}$, each with 2.5. mI of Krebs Ringer's phosphate solution per gram of tissue. To the resulting suspension were added 1.2 $\mathrm{mI}$ of a solution of $\mathrm{C}^{14}$-glutamic acid (3.8 X $10^{6} \mathrm{cpm} / \mathrm{mI}, 205$ peuries/mole) and $0.2 \mathrm{mI}$ of a solution of: $C^{I 4}$-glutamic acid ( $3 \times 10^{6} \mathrm{com} / \mathrm{m} I, 170$ peuries/ymole), the total activity being equivalent to II mauries. This whole-cell suspension was incubated at $37^{\circ}$ Co for 1.5 hours with constant agitation. After precipitation, tho protein was washed with cold. TCA and extracted into hot TCA. The gelatin-containing solution was dialyzed against distilled water at $4^{\circ}$ C. for 3 hours with one change in 
$-$

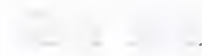

I<smiles>[Tl]</smiles> 


\section{$(40)$}

the external phase midway in the dialysis. The total radioactivity of the hot TCA extract decreased from 13,000 cpm before dialysis to $8,500 \mathrm{cpm}$ after dialysis.

The dialyzed solution was evaporated to $10 \mathrm{mI}$ and the polyhydroxamate derivative was prepared as before. The dry hydroxamate weighing $1.0590 \mathrm{~g}$ was dissolved in 20 ml of warm distilled water (ferric chloride test was positive for hydroxamic acid), and the polyhydroxamate-DIP derivative was formed. A fine yellow gelatin-hydroxamateDINP precipitate formed while the FDNB was being added to the hydroxamate solution. Franziblau noted that this occassionally happened when the pH was not well titrated, and that this precipitation limited the extent of the dinitrophenylation of the hydroxamate. During the extraction of the excess FDINB with anhydrous ether, a laboratory accident occurred. Which resulted in the loss of much of the gelatinDNP derivative. An attempt to extract the recovered material with petroleum ether was abandoned because a difficult emulsion formed. MaOH was added to the solution and Lossen rearrangement was promoted by heating - the gelatin went back into solution on heating. The rearranged solution was evaporated to a volume of $20 \mathrm{mI}$, made 6 N with respect to HCI and hydrolyzed at $110^{\circ}$ C. for 16 hours in vacuo. 



\section{Table $\mathrm{V}$}

A partial analysis of the pertinent products obtained

from the Los.sen rearrangenent of the hydroxamate-DNP deriwative of gelatin of 14 day old chick embryos.

Compound

Glutamic acid

Hydroxyproline

al pha, gamma-diamino butyric acid

Succinic semialdehyde $\frac{\text { Total yield }}{\text { (umoles) }} \frac{\text { Total activity }}{(\mathrm{com})}$

not assayed

195

138.5

not counted

not assayed

109

$3 \cdot 3$

0 


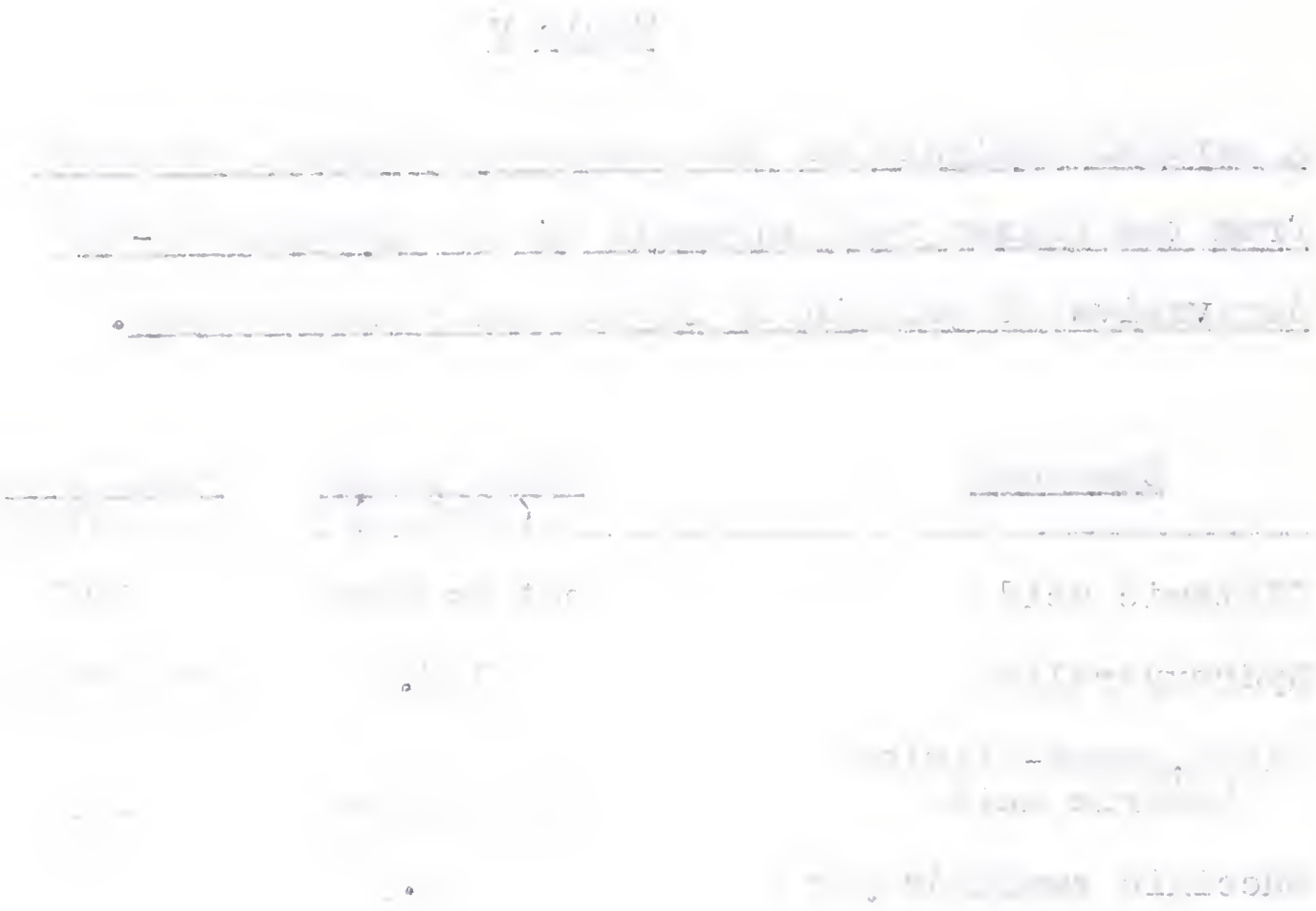


The hydrolysate was filtered and the 2,4-ainitrophenylhydrazone derivative was prepared from the entire hydrolysate. The resulting solution was evaporated to a convenient volume ror extraction, and the 2,4-ainitrophenylhydrazones were extracted in ethyl acetate. This solution was re-extracted and chromatographed in the usual manner. The: presence of succinic semialdehyde was veriried in both the tertiary arnyl alcohol - ethanol - water and in the water saturated butanol solvents. The compound was assayed and its radioactivity was determined. A known volume of: hydrolysate remaining after extraction was electrophoresed at: pH 6.0 , the hydroxyproline was eluted and assayed, and the glutamic acid was eluted and its radioactivity determined. The resolution in the area of the electrophorogram containing the dibasic amino acids was poor, probably because of the presence of a large amount of salt. Therefore the remainder of the sample which had not been electrophoresed was desalted and then electrophoresed at pH 6.0. A small amount of alpha, gamna-diaminobutyric acid. was identiried, eluted, and its radioactivity determined. In this experiment succinic semialdehyde was isolated and identified. However, in the absence of an unrearranged control, one cannot state, at this juncture, that the gamma- 

linkage must necessarily exist in gelatin derived from the chick embryo.

It is interesting to note from Table $\mathrm{V}$ that there was radioactivity present in the alpha,gamma-diaminobutyric acid and that none existed in the succinic semialdehyde. If the counts in alpha, gamma-diarnobutyric acid represent incoporation and if this succinic semialdehyde originated as a result of Lossen rearrangement of gama-glutarny I bonds in gelatin, there appear to be threepossible explanations for the absence of radioactivity from the succinic semialdehyde. First, this succinic semialdehyde might come from collagen already present in the embryos and not from newly synthesized collagen. However, this system is known to synthesize collagen actively, as Iukens. (30) has found that a 14-day whole-cell system from chick erabryos will incorporate labeled proline into hydroxyproline. As hydroxyproline, for all practical purposes in this instance, is only present in collagen, this incorporation serves as a proof of collagen synthesis. The second explanation that must be considered is that there is a delay between the incorporation of $\mathrm{C}^{\text {I }}$-glutamate into alpha-Iinkage and its incorporation into gamma-Iinkage, such that a measureable amount of activity is not incorporated into the ganma 


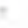


rearrangement product during the period of the incubation. This possibility will be discussed later. The third explanation is that the diaminobutyric acid may have been derived from non-collagenous protein, and the collagen may not be highly enough. Iabeled.

The low activity presented in Table $V$ for glutamic acid in relation to that of alpha, gama-diaminobutyric acid may be due, in part, to the sact that all of the glutamic acid was plated for counting and that the solution was not desalted before electrophoresis, as was the: alpha,gama-diaminobutyric acid sample. Both of these factors would tend to increase self-absorption. As most of the gelatin-hydroxarate-DIV derivative was lost, these values represent only a. small amount of the total activity of the original sample. In any event, i.t may be stated that the 14-day chick embryo whole-celI system apparentIy incorporated $\mathrm{C}^{14}$-gIutamic acid into hot TCA-extractable protein, and that a small portion of this activity was recoverable, after Lossen rearrangement, as the alpha-linkage rearrangement product. IV. The presence of the camma-glutamy peptide Iinlrage in the hot rCA-extractable protein of the 14-day chick embryo.

It was now decided to establish more rigorously whether or not the collagen-containing fraction of 14 day old chick embryos contained glutamic acid in the gamma-glutamyl Iinkage. 
A whole-cell incubation was prepared Irom 20 14-day White Leghorn chick embryos weighing $13.8 \mathrm{~g}$ each with $3 \mathrm{ml}$ of Krebs Ringer's phosphate solution per gram of tissue. The resulting suspension was incubated at $37^{\circ}$ C. for two hours. The protein was precipitated, washed and extracted twice with $5 \%$ TCA. The two hot TCA extracts were combined and extracted with ether - during the ether extraction a. white precipitate formed which was riltered out. The gelatin rich solution was dialyzed against distilled water at $4^{\circ} \mathrm{C}$. for three hours with the external phase being changed every hour. This dialyzed solution was evaporated to $20 \mathrm{mI}$ and redialyzed for 11 hours with one change of the external phase. The solution was then evaporated to $12 \mathrm{ml}$ and the polyhydroxamate derivative was made. The hydroxamate derivative weighing $1.6157 \mathrm{~g}$ was dissolved in $106 \mathrm{mI}$ of warm water and the solution was divided into two equal portions - one to be rearranged and one to remain as the unrearranged control. There were 463 umoles of hydroxamic acid groups in the $52 \mathrm{ml}$ submitted to Lossen rearrangement.

The control hydroxamate was hydrolyzed as usual afer bubbling nitrogen through the sample for five minutes. The other half of the gelatin hydroxamate was subjected to 

the Lossen rearrangement according to the usual procedure and was then hydrolyzed in' the same manner as the control. The 2,4-dinitrophenylhydrazone derivative of each hydrolysate was made, extracted, electrophoresed and chromatogra.phed. Succinic semialdehyde-2,4-dinitrophenylhydrazone was identified in the rearranged gelatin but not in the control. The identity of the compound was verified in two solvent systems, and it was assayed. After remova. of the 2,4-dinitrophenylhydrazones, the aqueous phase was evaporated to $2.0 \mathrm{ml}$ and desalted. After desalting, duplicate electrophoreses, elutions and assays were performed in order to demonstrate that the results obtained were not the result or differences in the degree of elution from the electrophorograms but represented real difierences. in the amino acid compositions of the control and rearranged gelatins.

In this experiment the presence of gamma-linked glutaric acid in the gelatin-rich hot TCA-extractable protein from the 14 -day chick embryo was affirmed. From Table VI it is evident that there was a great deaI Iess glutamic acid recovered from the rearranged gelatin than was recovered from the control. The fact that the amount of proline remained relatively constant, as indeed 

TabIe VI

Analysis of the products obtained on hydrolysis of the

Iossen rearranged gelatin from the 14-day chick erobryo

as compared with a suitable unrearranged control.

Compound.

Total pmoles recovered

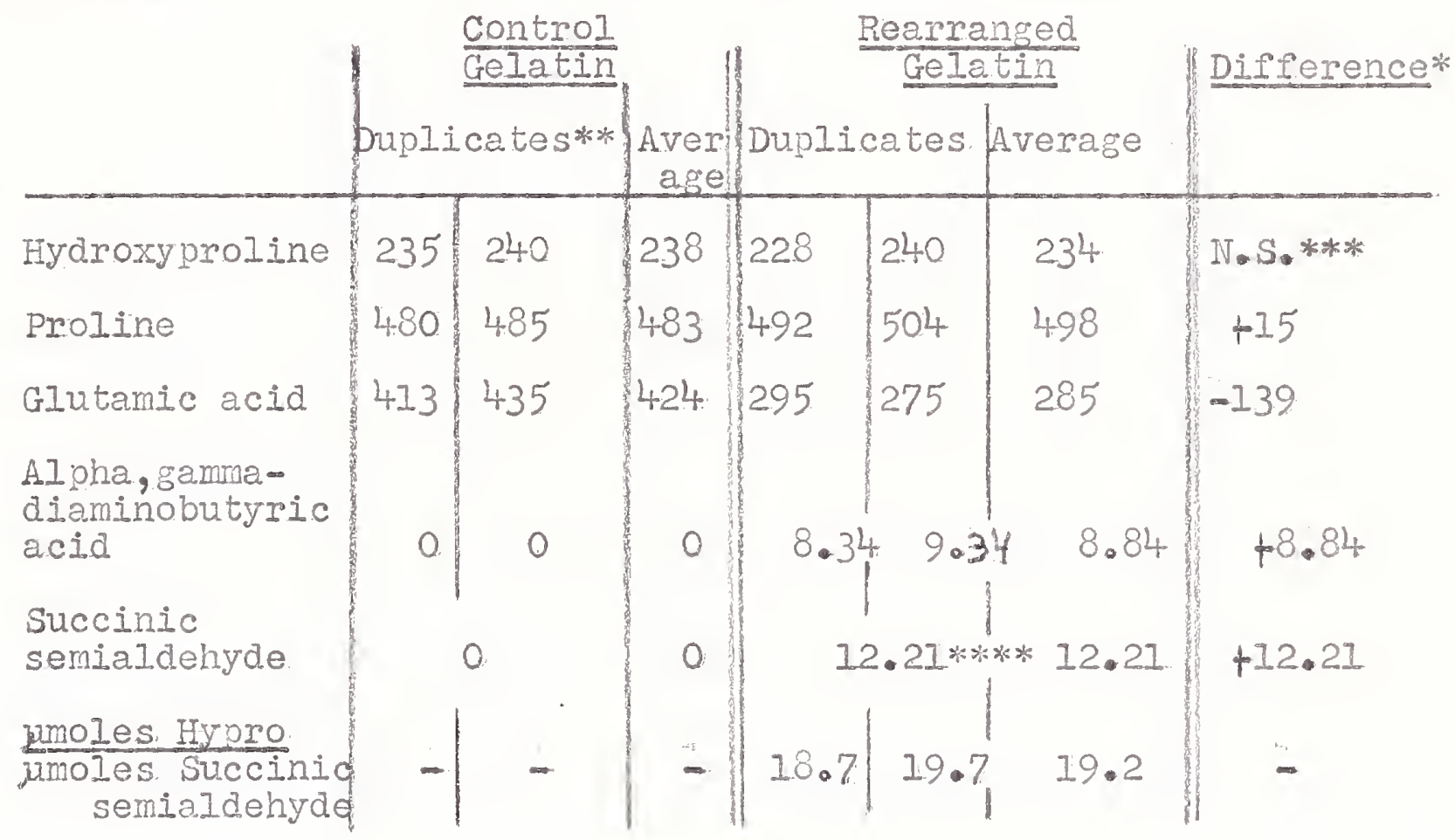

* Difference between control average and rearranged average. ** Duplicates $=$ Duplicate elutions from duplicate electrophoreses.

**** N. S. = Not significant.

****A single isolation and assay was done with succinic semialdehyde. 

it should for it is not involved in the rearrangement procedure, indicates that the decrease in glutamic acid units is real. The appearance of 21 , unoles of glutamic acid rearrangement products sill leaves 118 pmoles unaccounted for out of the 139 ymoles of the glutamic acid that disappeared as a result of the rearrangement. As the alpha,gamma-diaminobutyric acid was isolated from the same electrophorograms in the same way as the other amino acids that were analyzed, and as there is no evidence that this compound is unstable, it would not seem as though the discrepancy can be explained in terms of any large amounts of alpha, gamma-diaminobutyric acid being unaccounted for. It seems likely that the failure to account for the missing residues is due to the incomplete recovery of succinic semialdehyde as the phenylhydrazone. If the discrepancy Iies in the unrecovered succinic semialdehyde-2,4-dinitrophenylhydrazone, then it probably lies in the loss of succinic semialdehyde during hydrolysis, the incomplete formation of the hydrazone derivative, or in incomplete extraction procedures. Precautions against photic degradation or heat breakdown of the hydrazone derivative were observed during the experimental procedure. Because of the aforementioned discrepancy, an absolute statement of the number of gamma-linkages in gelatin cannot be made. However, one 

may conclude that there is at least one glutamic acid residue in gamma-peptide linkage for every 19 hydroxyproline residues in the gelatin-containing fraction derived from the 14-day chick embryo.

It might be worth repeating at this point that these investigations were Iocused on the estabishnent of an in vivo preparation in which the gamma-sutamyl bond. formation could be studied. Therefore it is not quantitative recovery of succinic semialdehyde that is important but rather the attainment of a high degree of purity for this cornpound. 



\section{(50)}

\section{Discussion}

Two of the questions that are raised by the presence of gamma-glutamyl linkages are that of how and when in the process of protein synthesir, as we conceive of it today, the bonds are formed. It is hoped that the work reviewed in the experimental section of this paper will, with greater refinement, lead to the establishment of a whole-cell system which may be used as a tool with which to study the enzyme or enzymes responsible for the formation of this gamma, linkage.

Figure 5. is a partial representation of the mechanism of protein synthesis as it is conceived of today. There are several stages in the synthetic process where the formation of the gamma-linkage may take place. First it may take place at the level of the formation of the aminoacyl-s-RIA complex. It is known from Ochoa (31) that the aminoacyladenylate-enzyme complex interacts With the corresponding transier RIA whereby the amino acid is esterified through its carboxyl group. to a hydrm oxyl residue on the terminal adenosine moiety of transier

\section{RINA.}

In the formation of the gamma-glutamyl bond, it may be that the gIutamic acid attaches to the S-RIA by its gamma-carboxyl group instead of by its alpha-carboxyl 

(51)

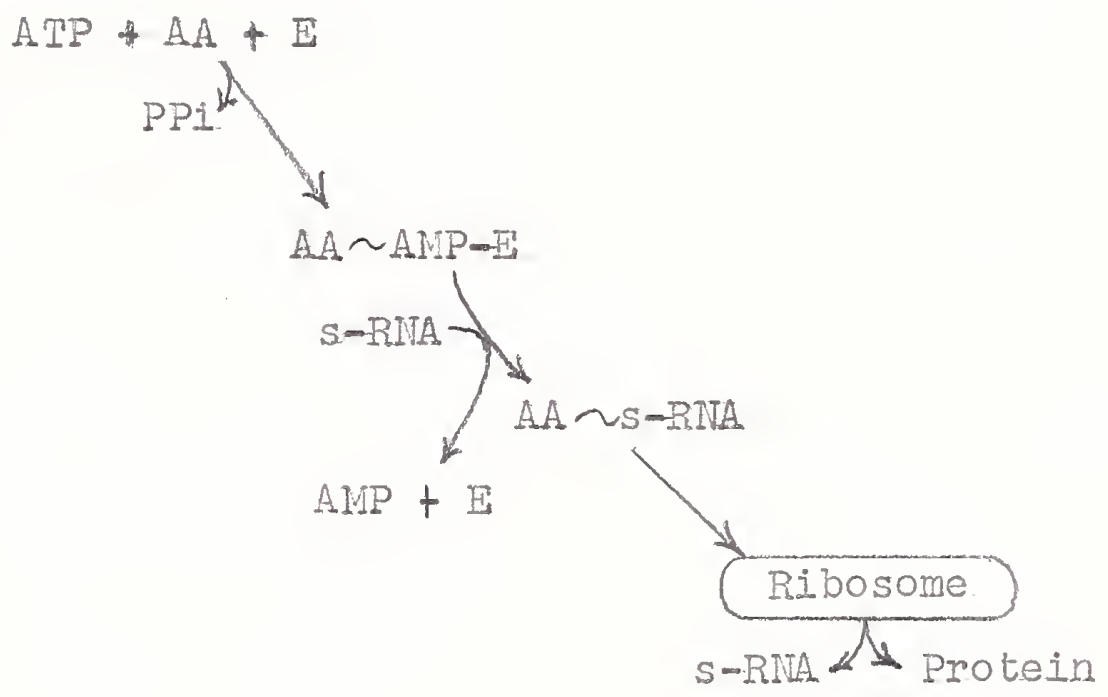

Pig. 5. Diagram of Protein Synthesis. $\quad E$ = enzyme, $A A=$ mino acid, $P P i=$ inorganic pyrophosphate, S-RIA = transfer RiA. 



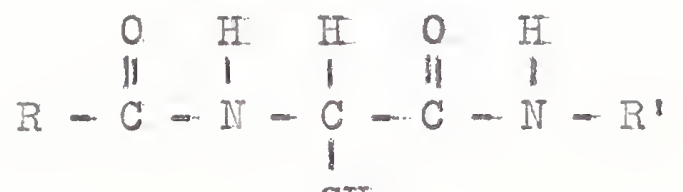

$$
\begin{aligned}
& \mathrm{CH}_{2}-\underset{\mathrm{C}}{\mathrm{CH}}-\mathrm{OH} \\
& \text { alpha-Iinkage }
\end{aligned}
$$

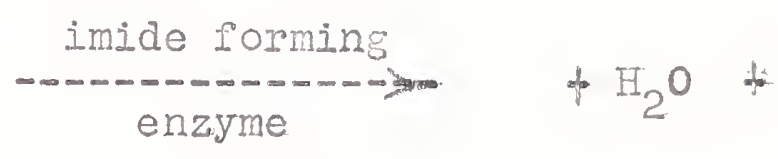

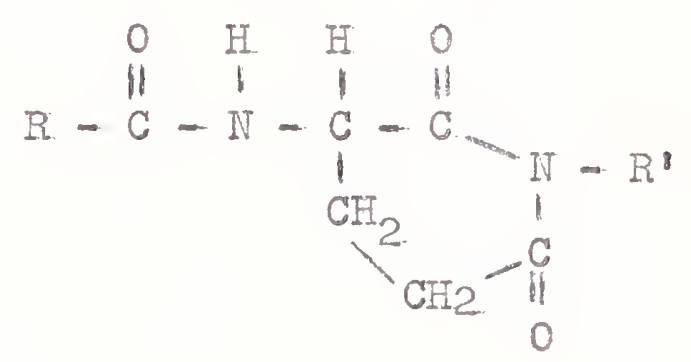

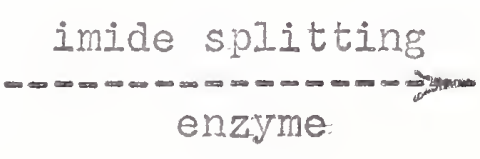

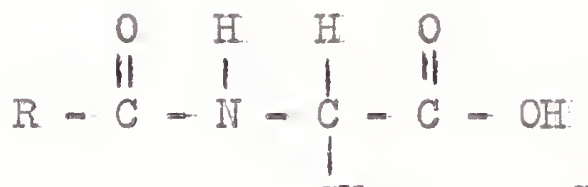

$$
\begin{aligned}
& \mathrm{CH}_{\mathrm{CH}_{2}} \underset{\mathrm{O}}{\mathrm{II}}-\underset{\mathrm{H}}{\mathrm{C}}-\mathrm{I}
\end{aligned}
$$

gamma-ininase

Fig. 6. Possible mechenism for intramolecular formation of gamna-glutamyl bonds. 

group. In the formation of the usual peptide linkage there is a specific distance between the carboxyl groupS-RIA bond and the amino group which is entering into peptide linkage with the emerging protein. If we are to assume the formation of a glutamyl-gamma-carboxylS-RNA, then we must assume that the increased amino group to carboxyl group distance is accounted for either by folding of the amino acid or by bending of the S-INNA. If one is to assume that it is at this level that the gamma-Iinkage is formed, then it may be necessary to assume thet there is a specific s-RNA for the glutamic acid entering gamma-linkage with a different code triplet or triplet order from the s-RIA of the glutamic acid entering into alpha-linkage.

A second possibility is that the gamma-linlrage may be formed by an intramolecular rearrangement of the alpha-linked amino acid. Such a rearrangement could take place before or after polymerization of collagen subunits into tropocollagen. The assumption in this case is that glutamic acid would have been incorporated into alpha-peptide linkage, an imide might then be formed and finaliy the alpha-carboxyl-nitrogen bond would be hydroljzed leaving the ganna-carboxyl group in peptide linkage. This would be the same type of reaction that was discussed in the introduction in relation to the possibility of 



\section{(54)}

artificial formation of the gamma-linkage during the synthesis of the hydroxamic acid derivative of gelatin by the method of Gallop, Seifter et al (14)。

If the formation of alpha- and gamma-Iintrages occurred at the same rate, as they presunably would if the gamabond is defined at the aminoacyl-s-RIA level, then one would expect the incorporation into gamma-Iinkage to show a similar variation with time as the incorporation into alpha-linkage. The same result would be expected if an intramolecular rearrangement took place in a short enough time after the incorporation of gutamic acid into the aIpha-Iinkage, such that the delay period could not be determined. If, however, intramolecular rearrangement accurs and there is a significant delay between incorporation into alpha-Iinked glutamic acid and its rearrangement into the gamma-Iinked form, then one might expect that the alpha-Iinked glutamyl units would contain radioactivity before activity appeared in the gammalinked units. This is a possible explanation for the presence of activity in the alpha, gamma-diaminobutyric acid and not in the succinic semialdehyde in experiment III. Further experimentation will be focused on the study of the rate of incorporation of radioactivity into the 

alpha - and gama-linkages, in order to gain some insight into the nature of the enzyme system responsible fior the gamma-bond formation. If it is shom that the bond is created by an intramolecular rearrangement, then I believe that this would be the first instance in which a peptide bond vas demonstrated to be created in this manner. 


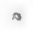




\section{(56)}

Summary

1.) It was found that a celi-free system from 7-day old chick embryos would incorporate $\mathrm{C}^{14}$-glutamic acid into the gela.tin-rich hot-TCA-extractable protein. After separation of macromolecular from small molecular components, some of the activity was recovered in the macromolecular fraction. The amount of incorporation in this system was small.

2) Commercial bovine Achilles tendon collagen was converted to the polyhydroxamic acid-DINP derivative and subnitted to Lossen rearrangement. Analysis of the hydrolysis products revealed the presence of succinic semialdehyde (the gamma-glutamyl-Iinkage rearrangement product) in both the rearranged gelatin and in an unrearranged control. The rearranged gelatin yielded 5.3 times as much succinic semialdenyde as it would be calculated to yield on the basis of the endogenous amount recovered from the unrearranged control. This collagen appears to contain at least 19 pmoles of gamma-glutamyl residues per 612 total glutamyl residues or per 676 residues of hydroxyproline. As discussed in the text, this is a minimal figure.

3) A whole-cell system of 20 14-day old chick embryos was incubated with $\mathrm{C}^{14}$-glutamic acid. After conversion 

to the polyhydroxamate-DNP derivative, the hot-TCAextractable protein was submitted to Lossen rearrangement. Succinic semialdehyde was recovered and found to contain no radioactivity, whereas the alpha, gama-diaminobutyric acid (alpha-Iinkage rearrangement product) which was. recovered contained a small amount of radioactivity. 4) The collagen-containing hot-TCA-extractable protein was extracted from 20 It-day embryos. After formation of the polyhydroxamate derivative, one hal of the solution was rearranged and the other was used as an unrearranged control. Analysis of the hydrolysis products revealed that both alpha- and gama-linkage rearrangement products were present in the rearranged gelatin hydrolysate but not in that of the control. Quantitative analysis revealed that there was at least one gamna-linked glutamic acid residue for every nineteen hydroxyproline residues, in the chick embryo collagen-containing hot TCA-extract.

5) A discussion of the possible mechanisms of gammabond formation was presented. 


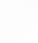

.

2 


\section{Bibliography}

I. Quastel, J.H., Stewart, C.P॰, and TunnicIiffe, H.E., Biochem. J. 17, 586 (1923).

2. Dakin, H.D., J. Biol. Chem. I, I7I (1905).

3. Hopkins, F.G., Biochem. J. 15, 286 (1921).

4o KendalI, E.C., Kason, H.I., and McKenzie, B.F., J. Biol. Chem. 87, 55 (1930).

5. Harrington, C.R., and read, I. If., Biochem。 J. 29, 1602 (1935)。

6. Ivanovics, G., and Bruckner, V., Zeitschrift fur Immunitatsforschung und Experimentelle Therapie. 20, 304. (1937).

7. Bovarnick, Mo, Jo Biol. Chem 145, 415 (1942).

8. Hanby, W• $\mathbb{E}_{\bullet}$, and Rydon, H.N., Biochem. J., 40, 297 (1946).

9. Kovacs, J•, and Bruckner, V., J. Chem. Soc. 4255 (I952).

10. Kovacs, J., Bruckner, V., and Kovacs, K•, J. Chem. Soc. 145 (1953).

11. Bruckner, V., Kovacs, J., and INagy, Ho, J. Chem. Soc., 149 (1953).

12. Waley, SoG., J. Chem, Soc., 517 (1955).

13. ChibnalI, A.C., Rees, M*W., and Richards, Fol., Biochem. J. 68,246 (1958). 

14. Gallop, P.M., Seifter, S., Iukin, M•, and Meilman, E., Jo Biol. Chem。 235, 2619 (I960).

15. Franzblau, C., "Unusual Iinkages in Collagen", Ph.D. Thesis, Sue Golding Graduate Division of Medical Sciences, Albert Einstein College of Medicine, Yeshiva University,. Obtained from University Microfilms, Inc., Ann Arbor, Michigan.

16. Gallop, P.M*, Seifter, S., and Meilman, M., Na.ture 183, 1659. (1959).

17. Sheehan, J.C., and Hlavaka, J.J., J. Org. Chem. 2I, 439 (1956)。

18. Einbinder, J., and Schubert, M., J. BioI. Chem. 188, 335 (1951)。

19. Littlefield, J.W., and Keller, E.B., J. Biol. Chem. 224, 13 ( 1957 ).

20. Blatt, A.H., in "Organic Synthesis" Z, 67 (I927).

21. Hendler, R.W., and Anfinson, C.B., J. Biol. Chem. 209, 55 (1954).

22. Peterkofsky, B., and Udenfriend, S., Biochem. and Biophys. Res. Comm. 6, 184. (1961).

23. Hirs, C.H.W., Moore, S., and Stein, W.H., J. Biol. Chem. 219, 623 (1956).

24. Moore, S., and Stein, W.H., J. Biol. Chem. I76, 367 $(1948)$. 

25. Seifter, S., Gallop, P.Mo, Michaels, S., and Meilman, E., J. Biol。Chem. 235, 2613 (1960).

26. Neuman, R.E., and Logan, M.A., J. Biol. Chem. 184, 299 (1950).

27. Leach, A.A., Biochem. J. 24, 70 (I960).

28. Chinard, F.P., J. Biol. Chem. 199, 91 (I952).

29. Waelsch, H. in "Methods in Enzymology", vol. III

(S.P. Colowick and N.0. Kaplan, ed.) p. 573, Academic Press, New York (1957).

30. Iukens, I., Personal Communication of unpublished ma.terial.

31. Ochoa, S., in "Informational Macromolecules", (H.J. Vogel, V. Bryson, and J.0. Lampen, ed.) p. 4, Academic Press, New York (I963). 


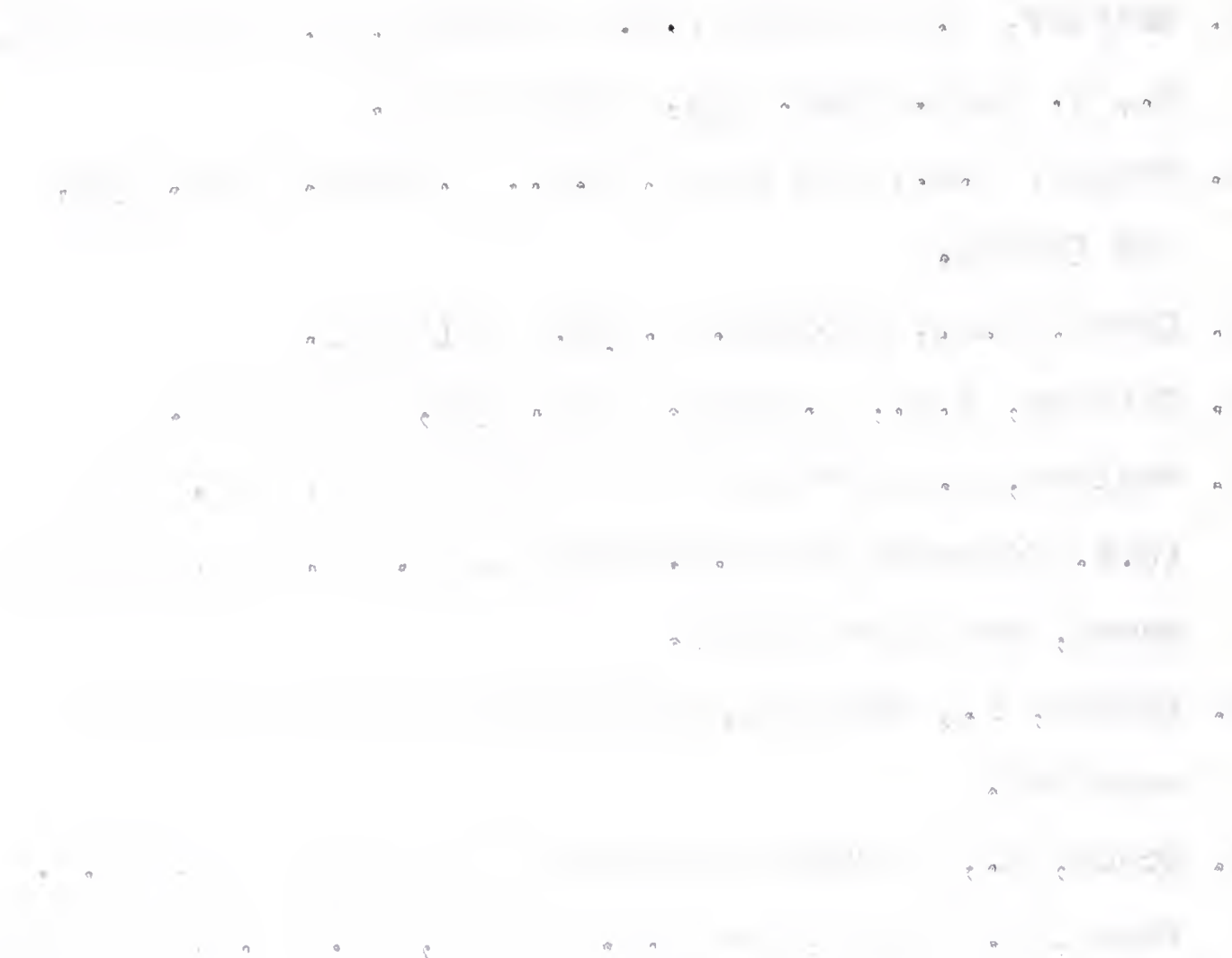






\section{YALE MEDICAL LIBRARY \\ Manuscript Theses}

Unpublished theses submitted for the Master's and Doctor's degrees and deposited in the Yale Medical Library are to be used only with due regard to the rights of the authors. Bibliographical references may be noted, but passages must not be copled without permission of the authors, and without proper credit being given in subsequent written or published work.

This thesis by has been used by the following persons, whose signatures attest their acceptance of the above restrictions. 
